Article

\title{
Study on Hysteresis Model of Welding Material in Unstiffened Welded Joints of Steel Tubular Truss Structure
}

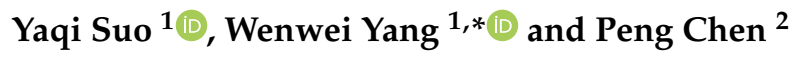 \\ 1 College of Civil and Hydraulic Engineering, Ningxia University, Yinchuan 750021, China; suoyaq@163.com \\ 2 Institute of Architectural Engineering, Huangshan University, Huangshan 245021, China; cp@hsu.edu.cn \\ * Correspondence: nxyangww@163.com
}

Received: 27 August 2018; Accepted: 16 September 2018; Published: 19 September 2018

check for updates

Featured Application: The main purpose of this study is to present a damage constitutive model of welded joints in steel structures, which can provide a basis for the precise design of steel structure joints. It can be popularized and applied in steel structure building, hydraulic steel structure pump house, dike and so on in field of civil engineering and hydraulic engineering. It also can be used for reference in the field of mechanical manufacturing.

\begin{abstract}
The weld form of intersecting joints in a steel tubular truss structure changes with the various intersecting curves. As the key role of joints in energy dissipation and seismic resistance, the weld is easy to damage, as a result the constitutive behavior of the weld is different from that of the base metal. In order to define the cumulative damage characteristic and study the constitutive behavior of welded metal with the influence of damage accumulation, low-cycle fatigue tests were carried out to evaluate overall response characteristics and to quantify variation of cyclic stress amplitude, unloading stiffness and energy dissipation capacity. The results show that the cyclic softening behavior of welding materials is apparent, however, the steel shows hardening behavior with the increase of cyclic cycles, while the cyclic stress amplitude, unloading stiffness, and energy dissipation capacity of the welding materials degenerate gradually. Based on the Ramberg-Osgood model and introducing the damage variable $D$, a hysteretic model of welding material with the effect of damage accumulation was established, including an initial loading curve, cyclic stress-strain curve, and hysteretic curve model. Further, the evolution equation of $D$ was also built. The parameters reflecting the damage degradation were fitted by the test data, and the simulation results of the model were proved to be in good agreement with the test results.
\end{abstract}

Keywords: damage accumulation; unstiffened welded joints of steel tube truss; welding material; low-fatigue test; evolution equation of damage accumulation; hysteretic model; parameter fitting

\section{Introduction}

Since steel tubular truss structures have fluent joint construction, favorable seismic behavior and a handsome visual effect, they have been widely used and researched in large public buildings such as stadiums, airports and bridges [1]. For example, 48 railway truss bridges were used as case studies by Khademi $[2,3]$ to study hybrid structural analysis and the procedures that were developed to enhance the load rating of railway truss bridges. There are also many other investigations for the behavior of trusses [4-12]. Still, the energy dissipation of a steel tubular truss structure depends mainly on the welded joint under earthquake. The intersecting line of the joint is a continuous spatial curve, which leads to the weld form needing constant change, so the welding process usually needs to be 
completed manually and residual strain can be found in the weld. In this condition, the welds under cyclic are prone to damage accumulation, which is observed to be a process that can cause immediate failure when the load is not large enough [13]. It should be pointed out that damage accumulation has such an important impact on the performance and service life of structure [14-19], and even several studies have focused on the damage detection of the construction structure and material [20-24], but there is little consideration of the weld damage accumulation in the study of seismic performance of steel tubular truss structure joints [25-28], and the difference of the constitutive relation between the welding material and base metal is often neglected. For instance, the research results of Wang [29] revealed that the welding material and its parent material of $304 \mathrm{~L}$ steel have different hardening laws and damage evolution laws under cyclic loading. In addition, the size and shape of the yield surface of material will change continuously under cyclic loading, which is quite different from the constitutive behavior under a monotonic load. If the stress and strain distribution of the large cyclic deformation is calculated only by the plastic model, such as the perfect elastic-plastic and bilinear model that is always used for monotonous loading, it will result in a greater difference from the actual process.

It is critical to find a constitutive model that can be used to describe the cyclic characteristics of welding materials. Shen [30,31] put forward a hysteresis model of steel, which has been considered as the damage accumulation of steel under cyclic loads. The model has good applicability but did not consider the effect of nonlinear hardening. A constitutive model of piezoelectric materials with damage is presented by Sun et al. [32], meanwhile, the evolution for damage accumulation is developed by using the finite difference method and the Newmark scheme. Shi et al. [33] conducted the cyclic experiments of Q235B and Q345B structural steel, and a hysteretic model of structural steel under cyclic loading was proposed. The model has proven to be effective and can be used in finite element analysis. Van Do et al. [34] derived a cyclic constitutive model about a super duplex stainless steel, the model was established based on the Chaboche and the Burlet and Cailletaud model, which can reflect the nonlinear kinematic hardening rule. Wang et al. [35] studied the cyclic behavior of law yield point steels (LYP100 and LYP160), then the Ramberg-Osgood model was used to fit the cyclic skeleton curves of low yield point (LYP) and the parameters for the combined hardening model were obtained. The form of the Ramberg-Osgood relationship was also verified and can be used to define the cyclic stress-strain curves of structural carbon steel by Nip et al. [36]. Besides, the difference between the Chaboche model and the Ramberg-Osgood model in simulating and analyzing the cyclic loading characteristics of low alloy 42CrMo steel was compared and analyzed by Basan et al. [37], which showed that the two models have similar results on the premise of stable material performance. In recent years, the Ramberg-Osgood model has been adopted in other research to describe the stress-strain constitutive relation of metallic materials [38-42].

In conclusion, numerous previous studies have shown that the Ramberg-Osgood model [43] has good applicability in describing the cyclic stress-strain relationship of metallic materials, but little related research has taken into account the damage accumulation in the hysteretic model and constitutive model. On the other hand, the study showed that there are obvious differences in the cyclic characteristics between the welding material and its parent material. For weld, Corigliano et al. [44] investigated the behavior of welded T-joints under low-cycle fatigue though tests and nonlinear finite element analysis, which has contributed to the predicting model of fracture and fatigue behavior for welded joints. Some other studies [45-50] relating to the constitutive model of the different materials of a weld also should be mentioned, but the research on the cyclic constitutive model for the welding material of steel tubular truss structure joints has still not been fully carried out, and there is also a lack of model parameters that can reflect the damage deterioration of the welding material. Thus, the cumulative damage evolution rule [51-55] of welding materials also should be paid attention to. Consequently, an experimental investigation was performed in this research on the welding material of steel tubular truss structure joints under law cyclic loading. The experimental details are presented and the observations of test, the stress-strain responses, as well as the hysteretic properties and energy dissipation capacity, were discussed. The cumulative evolution law of the welding material 
was obtained through experiments. Based on the experimental results, a damage cumulative evolution equation of welding material was established, and a hysteresis model of welding material considering damage cumulative effects was constructed. Then, the damage parameters of the hysteresis model were fitted by the experimental data. Finally, the results calculated by the hysteretic model were compared with the experimental results.

\section{Experimental Study}

\subsection{Specimen Design}

There are butt welds and fillet welds in the welded joints of the steel tubular truss structures, as illustrated in Figure 1. For instance, there are butt welds near the crown points, fillet welds around the heel point, and fillet welds around the saddle point. According to the two kinds of weld forms and welding process, the model of $\mathrm{T}$ type fillet welds and butt welds were welded by the advanced welders, which fully penetrated the Q235 and Q345 law carbon steel produced in accordance with Chinese standard [56] that were used as the base material. The welding process satisfied the requirements prescribed in the Chinese national standard for the welding of a steel structure (JGJ81-2002) [57]. Then, the standard specimens of weld metal, steel in heat-affected zone, and steel before welding were extracted from the model. The butt weld and the fillet weld model as the sampling position of the standard specimens are shown in Figure 2. The steel specimens are extracted in vertical and parallel to rolling directions to study whether the rolling direction has an effect on the cyclic characteristics of the specimens. The specific dimensions of the specimens are depicted in Figure 3a. The specimens were marked based on the steel strength grade, welding type, and loading pattern, as presented in Table 1 , where the labeled numbers of (1)-(3) in each group were designed for different loading patterns.

Table 1. Labels of the specimens of low cycle fatigue test.

\begin{tabular}{|c|c|c|c|c|c|c|c|c|}
\hline \multirow{3}{*}{$\begin{array}{c}\text { Type for } \\
\text { Base Metal }\end{array}$} & \multicolumn{2}{|c|}{ Steel Specimen before Welding } & \multicolumn{3}{|c|}{ Welding Material } & \multicolumn{3}{|c|}{ Steel of Heat-Effected Zone } \\
\hline & \multirow{2}{*}{$\begin{array}{l}\text { Parallel Rolling } \\
\text { Direction }\end{array}$} & \multirow{2}{*}{$\begin{array}{l}\text { Vertical Rolling } \\
\text { Direction }\end{array}$} & \multirow{2}{*}{ Butt Weld } & \multicolumn{2}{|c|}{ Fillet Weld of T Type } & \multirow{2}{*}{ Butt Weld } & \multicolumn{2}{|c|}{ Fillet Weld of T Type } \\
\hline & & & & Left & Right & & Left & Right \\
\hline Q235 & $\begin{array}{c}\text { SA1 } \\
(1)-(3)\end{array}$ & $\begin{array}{l}\text { SA2 } \\
(1)-(3)\end{array}$ & $\begin{array}{l}\text { WA1 } \\
(1)-(3)\end{array}$ & $\begin{array}{l}\text { WA2 } \\
(1)-(3)\end{array}$ & $\begin{array}{l}\text { WA3 } \\
(1)-(3)\end{array}$ & $\begin{array}{l}\text { HA1 } \\
(1)-(3)\end{array}$ & $\begin{array}{l}\text { HA2 } \\
(1)-(3)\end{array}$ & $\begin{array}{l}\text { HA3 } \\
(1)-(3)\end{array}$ \\
\hline Q345 & $\begin{array}{c}\text { SB1 } \\
(1)-(3)\end{array}$ & $\begin{array}{c}\text { SB2 } \\
(1)-(3)\end{array}$ & $\begin{array}{l}\text { WB1 } \\
\text { (1)-(3) }\end{array}$ & $\begin{array}{c}\text { WB2 } \\
(1)-(3)\end{array}$ & $\begin{array}{c}\text { WB3 } \\
\text { (1)-(3) }\end{array}$ & $\begin{array}{c}\text { HB1 } \\
(1)-(3)\end{array}$ & $\begin{array}{l}\text { HB2 } \\
(1)-(3)\end{array}$ & $\begin{array}{c}\text { HB3 } \\
\text { (1)-(3) }\end{array}$ \\
\hline
\end{tabular}
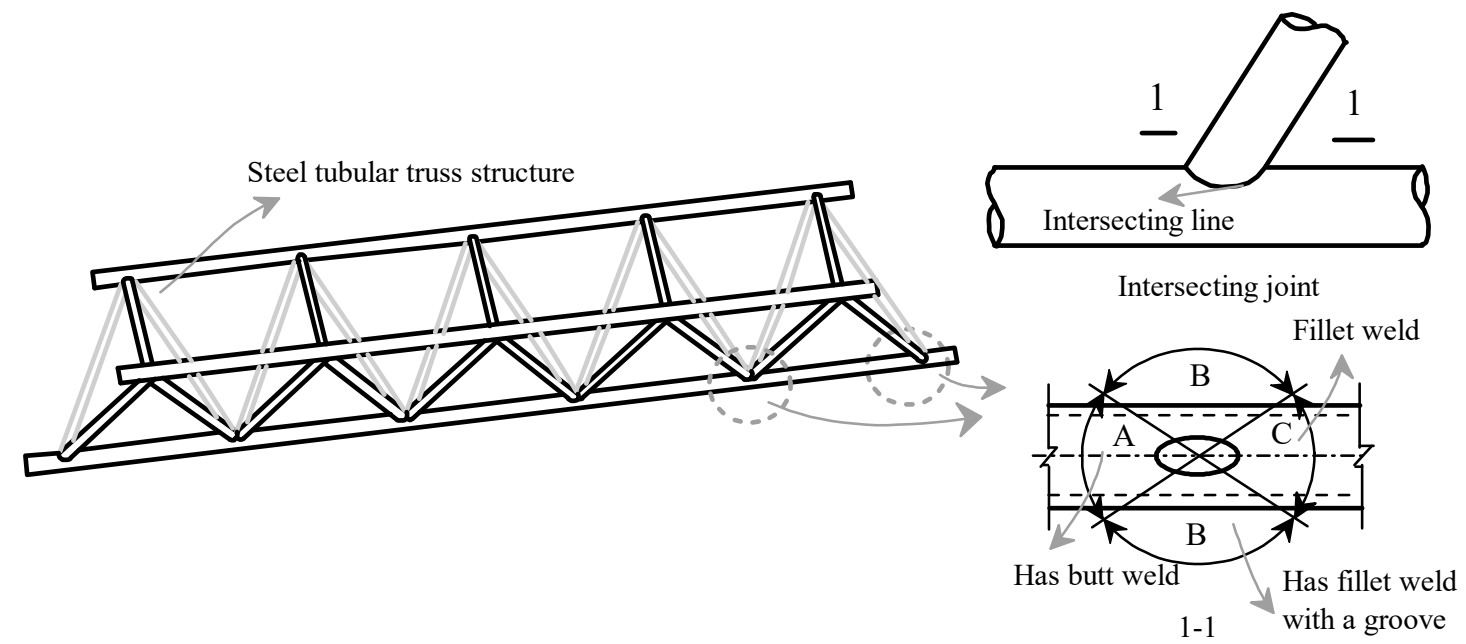

Figure 1. Weld distribution of intersecting joints in steel tubular truss structure. 


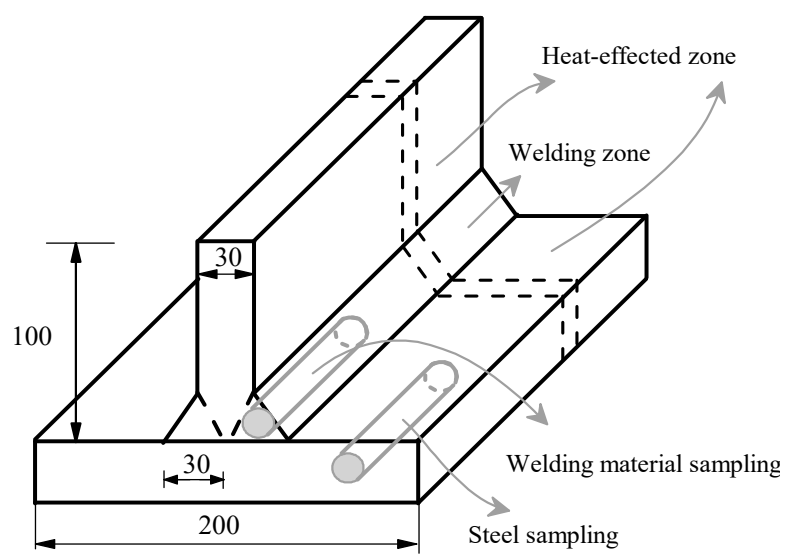

(a)

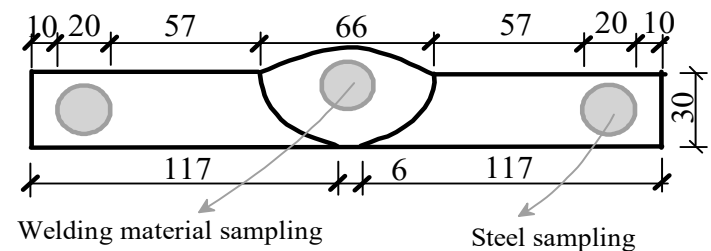

(b)

Figure 2. Acquisition of the standard specimen. (a) Sampling of fillet weld(mm); (b) Sampling of butt weld (mm).

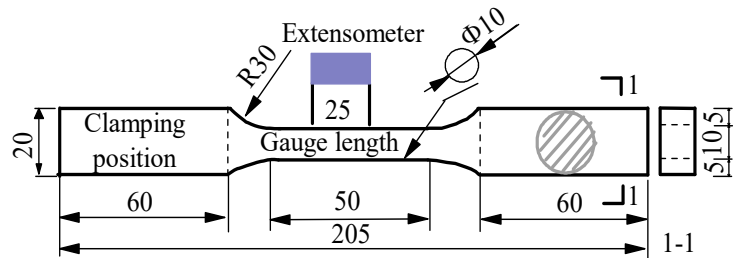

(a)

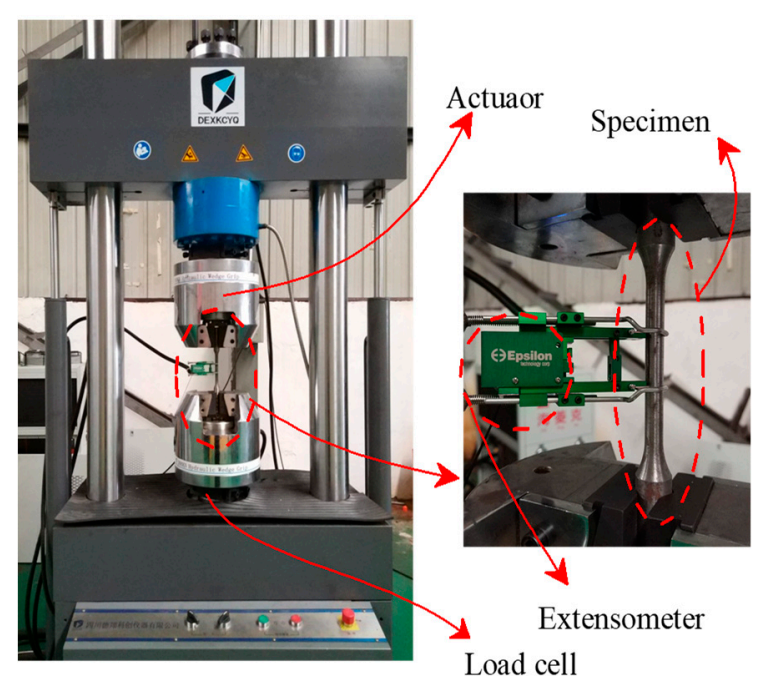

(b)

Figure 3. Experimental specimen and setup. (a) Dimensions of specimen (mm); (b) Experimental setup and instrumentation.

\subsection{Test Procedure}

The specimens were loaded by an electro-hydraulic servo fatigue testing machine (DPL-9010, DEXKC, Chengdu, China), as shown in Figure 3b. Low cyclic loads were applied to test the cyclic behavior of the specimens. And the loading was realized by a hydraulic servo drive technology and controlled by computer. As the rapid development of deformation after yielding, strain controlled loading was adopted though the measured displacement data from the extensometer over the gage length (see Figure $3 \mathrm{a}, \mathrm{b}$ ). The gage length and the elongation of the extensometer are $25 \mathrm{~mm}$ and $10 \%$ respectively, therefore, the strain values could be obtained from the displacements divided by $25 \mathrm{~mm}$. The specimens were loaded until fracture, although the extensometer was dismantled and replaced by the displacement control when the wide fatigue cracks appeared in the specimen or the stress amplitude attenuated to around $50 \%$, so as to prevent the extensometer from being damaged caused by the sudden breaking of the specimen. On the other hand, the stress could be obtained from the load divided by the section area of the standard specimen. After the test, the stress-strain data were outputted to depict the hysteretic curves.

The loading patterns, which are described in Figure 4, for weld metal, steel in the heat-affected zone and steel before welding were imposed. As showed in Figure 4, the tensile and compress cyclic 
loads were applied in the form of symmetrical triangular waves. The loading rate is $0.5 \%$, and the strain ratio is $-1\left(\varepsilon_{\max } / \varepsilon_{\min }=-1\right)$. In order to study the effect of the loading strain amplitude on the hysteretic model, the loading strain amplitude of each group of specimens ranges from $0.2 \%$ to $0.5 \%$, that is, the loading strain amplitudes of the specimens numbered (1), (2), (3) are $0.25 \%, 0.35 \%$ and $0.45 \%$, for specimens of weld, steel, and the heat-effected zone. As a result, Figure 4 a corresponds to all No. (1) specimens, Figure $4 \mathrm{~b}$ corresponds to all No. (2) specimens, and Figure $4 \mathrm{c}$ corresponds to all No. (3) specimens. Table 2 summarizes the primary mechanical parameters of the specimens, which were obtained by uniaxial tensile test (averaged over three specimens).

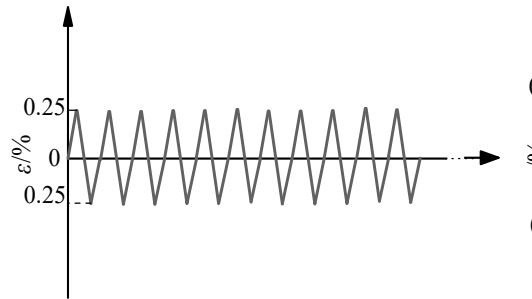

(a)

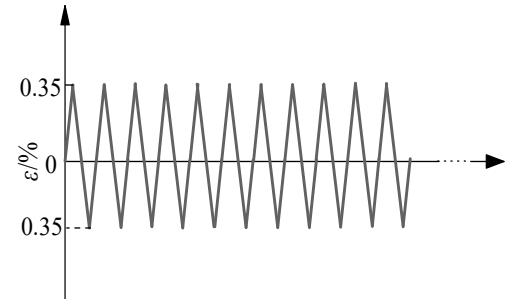

(b)

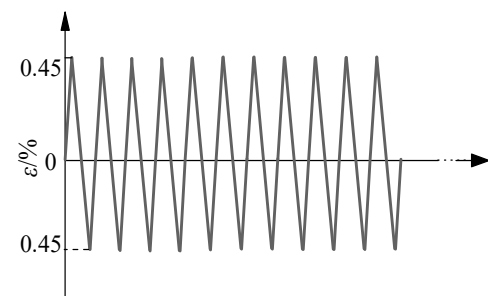

(c)

Figure 4. Cyclic loading patterns. (a) For all No. (1) specimens; (b) For all No. (2) specimens; (c) For all No. (3) specimens.

Table 2. Mechanical parameters under monotonic loading.

\begin{tabular}{cccccc}
\hline Specimens & $f_{\mathbf{y}} / \mathbf{M P a}$ & $f_{\mathbf{u}} / \mathbf{M P a}$ & $\varepsilon_{\mathbf{y}} / \%$ & $\varepsilon_{\mathbf{u}} / \%$ & $E / \mathbf{G P a}$ \\
\hline SA1 & 268.8 & 430.1 & 0.15 & 16.3 & 207.1 \\
SA2 & 268.1 & 429.7 & 0.15 & 16.4 & 195.7 \\
WA1 & 391.7 & 497.6 & 0.16 & 13.0 & 239.7 \\
WA2 & 401.6 & 486.8 & 0.17 & 12.7 & 233.6 \\
WA3 & 402.3 & 497.8 & 0.17 & 11.8 & 213.0 \\
HA1 & 254.7 & 433.5 & 0.13 & 15.8 & 223.3 \\
HA2 & 259.2 & 423.6 & 0.13 & 15.5 & 203.6 \\
HA3 & 255.4 & 422.9 & 0.13 & 15.6 & 204.5 \\
\hline SB1 & 365.6 & 532.6 & 0.16 & 16.0 & 216.1 \\
SB2 & 385.1 & 540.1 & 0.15 & 15.2 & 217.9 \\
WB1 & 420.1 & 498.1 & 0.15 & 12.7 & 235.5 \\
WB2 & 426.3 & 508.5 & 0.17 & 11.7 & 251.0 \\
WB3 & 431.5 & 525.4 & 0.17 & 11.3 & 217.6 \\
HB1 & 365.2 & 531.0 & 0.16 & 16.0 & 235.0 \\
HB2 & 357.8 & 530.5 & 0.15 & 15.3 & 225.1 \\
HB3 & 358.5 & 527.6 & 0.16 & 15.2 & 218.3 \\
\hline
\end{tabular}

\section{The Test Results and Discussion}

\subsection{Failure Model and Damage Processes}

Figure 5 shows three stages of cumulative damage of welded specimens under low-cycle cyclic loading. The first stage that can be observed is the initial stage of damage process, which was characterized by the initiation of cracks on the surface of the specimen. As the loading cycles increased, micro cracks could be observed on the surface of the specimen, as shown in Figure 5a. This stage was typically short in duration, and the crack occurred in the slip band of the micro-defect or weak position of the material, which then developed internally along the direction of the maximum shear stress $\left(45^{\circ}\right.$ with the principal stress). As shown in Figure 5b, with the increase of loading cycles, the damage accumulated continually and the specimen gradually entered into the second stable stage, in which the crack began to widen and the direction of the crack propagation gradually turned perpendicular to the principal stress. This stage has the longest duration and the crack developed relatively slow, 
which is considered to be the main stage of damage accumulation. The last stage is the failure stage, as shown in Figure 5c, where the specimens were fractured at the maximum main crack.

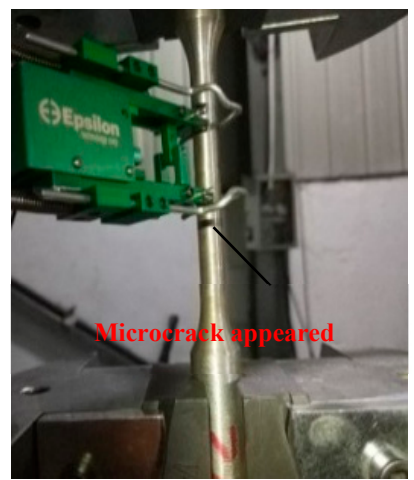

(a)

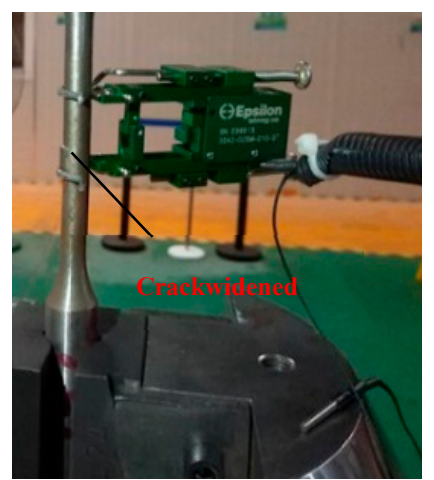

(b)
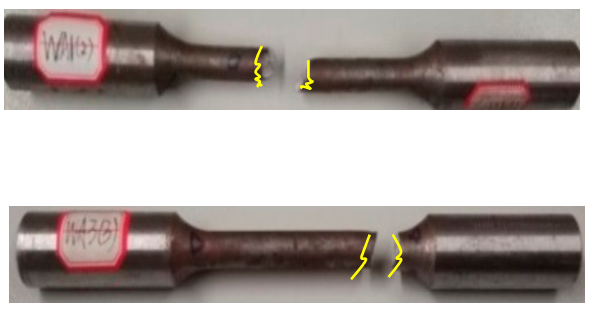

(c)

Figure 5. Damage process of welded specimen in low cycle fatigue test. (a) Crack appeared in specimen;

(b) Crack develop; (c) Specimen fractured at the maximum main crack.

\subsection{Cyclic Behavior and Damage Analysis}

The number of semi-cycles until the specimens were fractured are listed in Table 3, which are about the welding material and its base material of welded joints in the steel tubular truss structure. It can be revealed by Table 3 that the cyclic life of the welded metal is less than that of the base metal with the same working condition, which indicates that the speed of damage accumulation of the welding material is faster than that of the steel, in other words, the welding materials accumulate damage more easily than the base materials. The cycling life of the welding materials decreases with the increase of the loading strain amplitude. The higher the strain amplitude level, the faster the degradation rate of the specimens under cyclic loading, and resulting in earlier destruction. Table 3 also shows that the influence of the steel rolling direction on the cycling life of steel is mainly reflected in Q235 steels.

Table 3. Number of half cycles of welding material and steel.

\begin{tabular}{ccccccccccc}
\hline \multirow{2}{*}{ Specimens } & \multicolumn{4}{c}{ Welded Specimens } & \multicolumn{4}{c}{ Steel Specimens } \\
\cline { 2 - 11 } & WA1 & WA2 & WA3 & WB1 & WB2 & WB3 & SA1 & SA2 & SB1 & SB2 \\
\hline$(1)(0.25 \%)$ & 3091 & 3810 & 3430 & 4351 & 4205 & 4293 & 4321 & 3789 & 4766 & 4703 \\
$(2)(0.35 \%)$ & 1865 & 1801 & 1831 & 2223 & 1992 & 1973 & 2109 & 1983 & 2525 & 2607 \\
$(3)(0.45 \%)$ & 1089 & 994 & 977 & 1559 & 1165 & 1106 & 1301 & 976 & & 1639 \\
\hline
\end{tabular}

The cyclic stress-strain $(\sigma-\varepsilon)$ curves of welded specimens and steel specimens are shown in Figures 6 and 7, respectively, in which the abscissa axis represents the strain of the specimen, and the ordinate axis represents the stress. It can be seen that the stress-strain constitutive relation of the materials reflected by the hysteretic curves changes with the increase of cyclic cycles under cyclic loading. As can be studied analytically, each of the semi-cycles contains two main stages, that is, the loading stage with curvilinear segment and the unloading stage with approximate liner segment, respectively. There is an apparent difference between the curves of welded materials and steels. The welded material shows obvious damage degradation, that is, the stress amplitudes increase slightly only at the beginning of the loading, then decrease gradually with the increase of cyclic cycles, which indicate that the cyclic softening behavior of the welding material is apparent as the imposed displacement cycles increase, on the contrary, the steel shows cyclic hardening characteristics. During the cycling process, the stress level of the welded materials is higher than that of the steel specimens under the same working condition, but the cycling life of the welded material is less than that of the steel. This indicates that the welded material was hardened to a certain extent 
due to the influence of complex factors such as the welding process with high temperature, but its ability of plastic deformation has been weakened, which makes the welded material more prone to damage accumulation and damage degradation than its base metal. Furthermore, it is suggested that the constitutive relation between the welded metal and its base metal should be considered distinguishingly and the damage accumulation should be considered in the cyclic nonlinear analysis of the direct welded joints of the tubular truss structures.

Figure 6 contains the hysteretic curves of the welding materials under different conditions of weld seam types, base metal types, and loading strain amplitudes. It can be seen from the curves that in addition to the degradation of the cyclic stress amplitude, the hysteretic curve of the welded metal shows a gradual "down" trend with the increase of the cyclic cycles, that is, the damage accumulation caused degradation of bearing capacity and unloading stiffness. Furthermore, the area around the hysteresis loop decreases with the increase of the cyclic cycles, which means that the damage accumulation can also lead to a decrease in energy dissipation capacity. In a word, under cyclic loading, the damage of the welded metal was expanding and accumulating, which is the main reason for the performance degradation until the final failure. For the existing constitutive models of metallic materials, the damage degradation behavior of welded materials has been seldom considered and the failure mechanism of materials and structures due to damage accumulation cannot be accurately revealed.

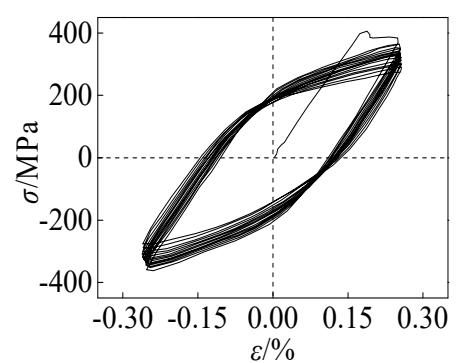

(a)

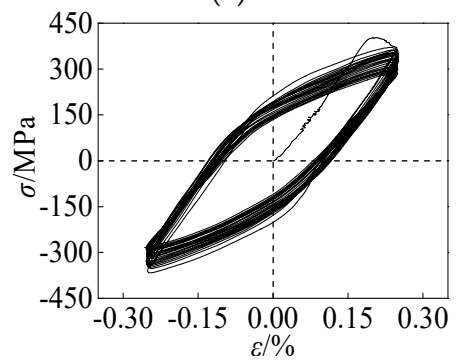

(d)

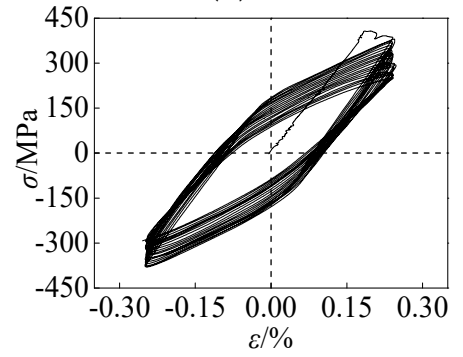

(g)

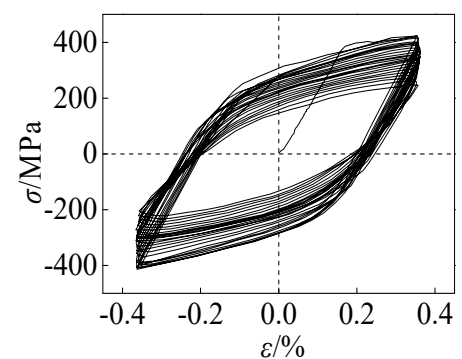

(b)

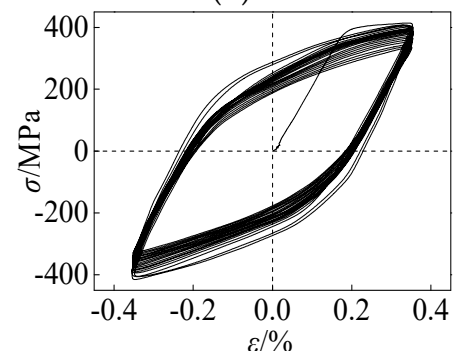

(e)

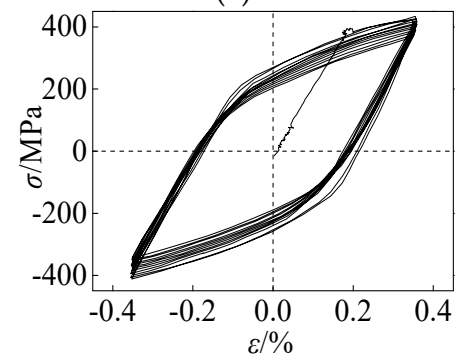

(h)

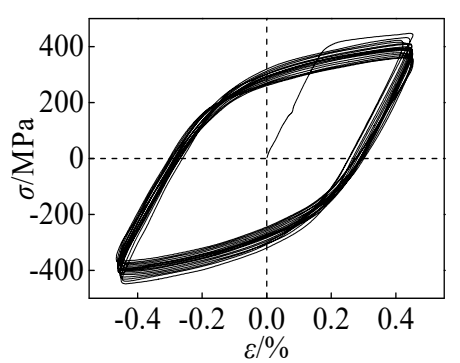

(c)

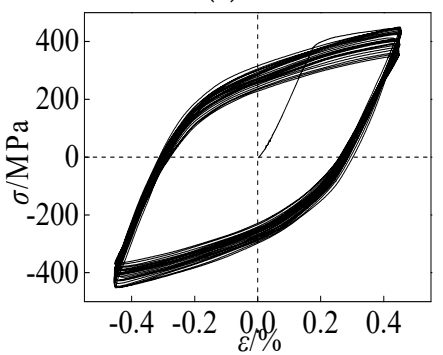

(f)

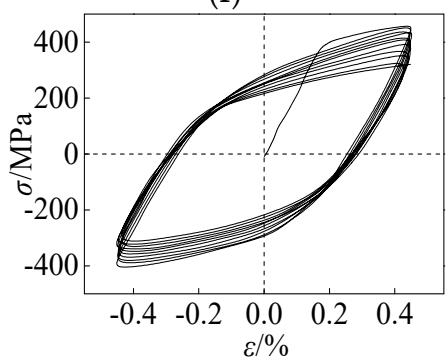

(i)

Figure 6. Cont. 


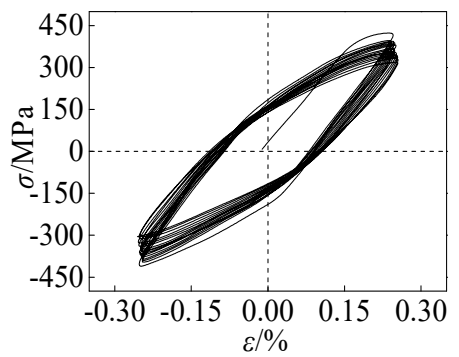

(j)

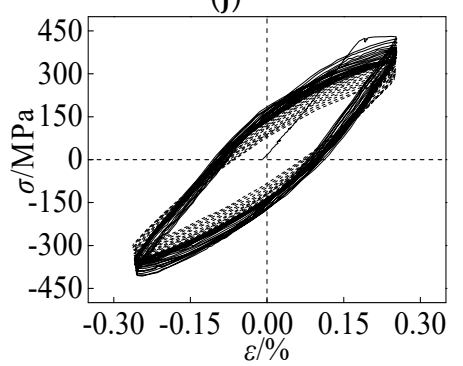

(m)

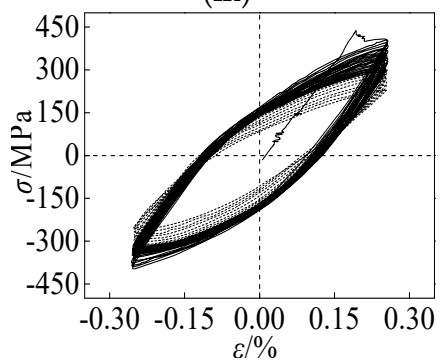

(p)

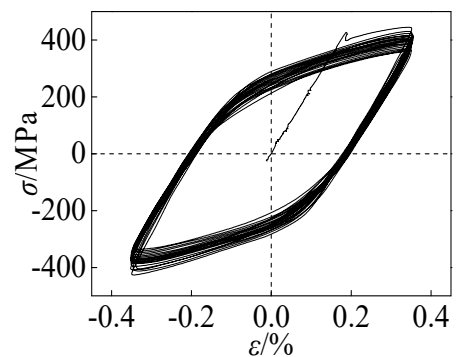

(k)

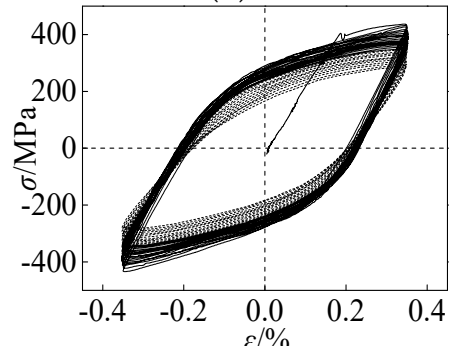

(n)

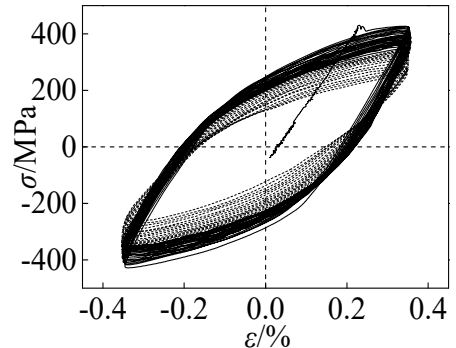

(q)

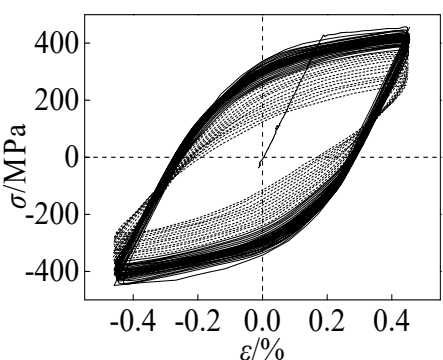

(1)

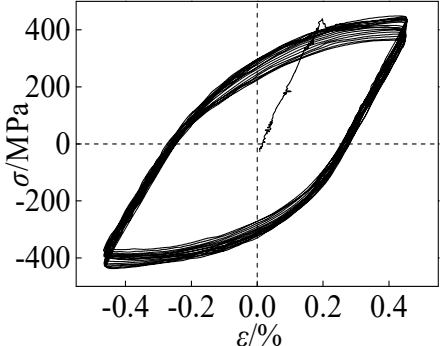

(o)

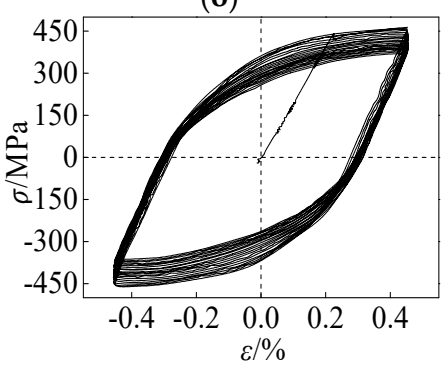

(r)

Figure 6. Stress-strain $(\sigma-\varepsilon)$ hysteresis curve of the welded specimen. (a) WA1 (1) $\varepsilon_{\max }=0.25 \%$; (b) WA1 (2) $\varepsilon_{\max }=0.35 \%$; (c) WA1 (3) $\varepsilon_{\max }=0.45 \%$; (d) WA2 (1) $\varepsilon_{\max }=0.25 \%$; (e) WA2 (2) $\varepsilon_{\max }=0.35 \%$; (f) WA2 (3) $\varepsilon_{\max }=0.45 \%$; (g) WA3 (1) $\varepsilon_{\max }=0.25 \%$; (h) WA3 (2) $\varepsilon_{\max }=0.35 \%$; (i) WA3 (3) $\varepsilon_{\max }=0.45 \%$; (j) WB1 (1) $\varepsilon_{\max }=0.25 \%$; (k) WB1 (2) $\varepsilon_{\max }=0.35 \%$; (1) WB1 (3) $\varepsilon_{\max }=0.45 \%$; (m) WB2 (1) $\varepsilon_{\max }=0.25 \%$; (n) WB2 (2) $\varepsilon_{\max }=0.35 \%$; (o) WB2 (3) $\varepsilon_{\max }=0.45 \%$; (p) WB3 (1) $\varepsilon_{\max }=0.25 \%$; (q) WB3 (2) $\varepsilon_{\max }=0.35 \%$; (r) WB3 (3) $\varepsilon_{\max }=0.45 \%$.

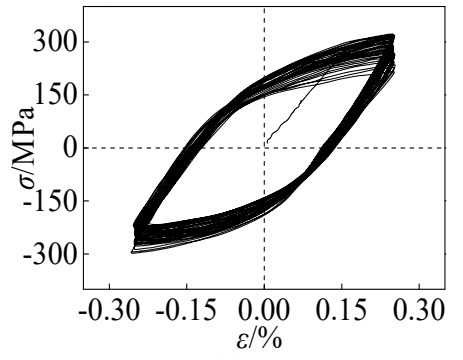

(a)

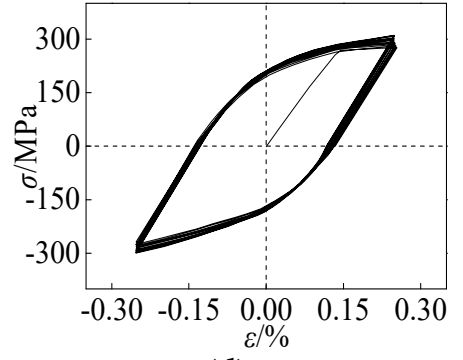

(d)

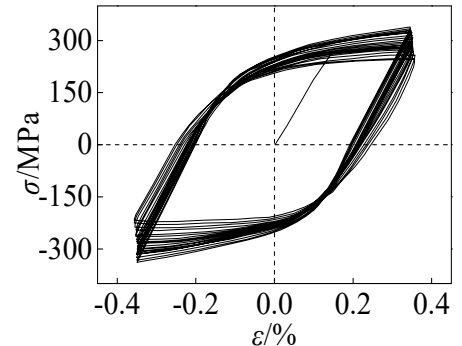

(b)

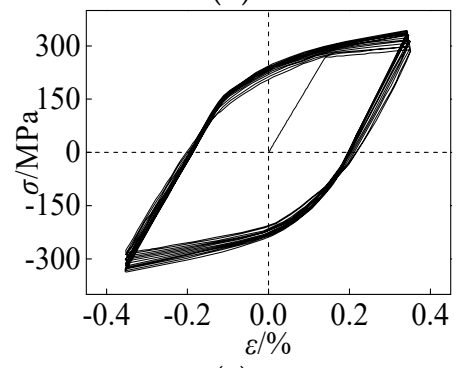

(e)

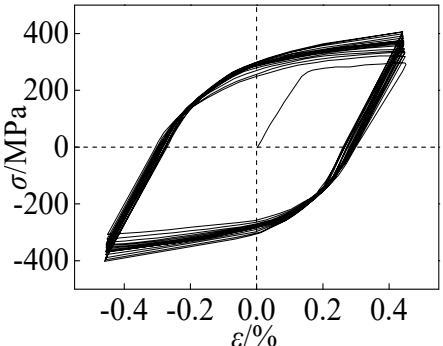

(c)

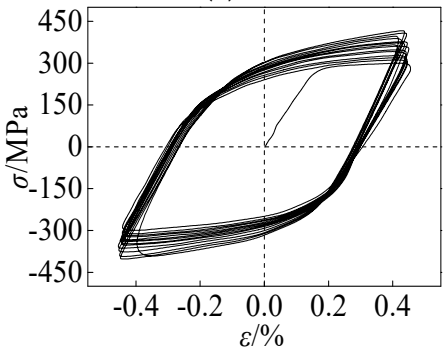

(f)

Figure 7. Cont. 


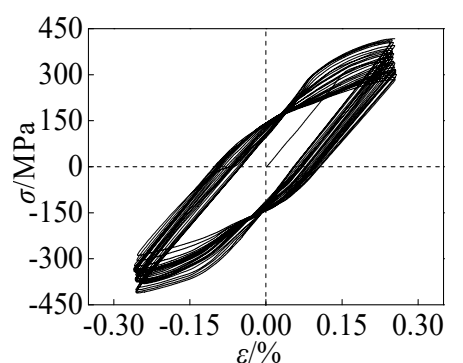

(g)

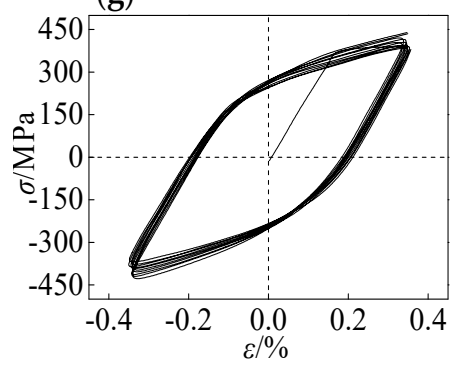

(j)

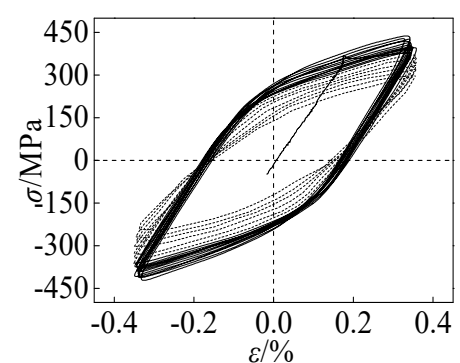

(h)

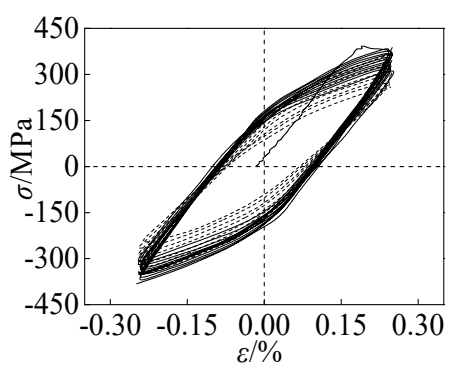

(i)

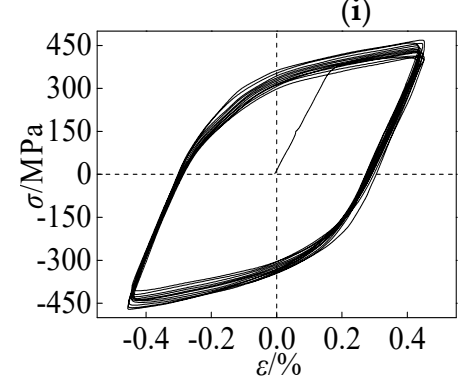

(k)

Figure 7. Stress-strain $(\sigma-\varepsilon)$ hysteresis curve of the steel (base metal) specimen.(a) SA1 (1) $\varepsilon_{\max }=0.25 \%$;

(b) SA1 (2) $\varepsilon_{\max }=0.35 \%$; (c) SA1 (3) $\varepsilon_{\max }=0.45 \%$; (d) SA2 (1) $\varepsilon_{\max }=0.25 \%$; (e) SA2 (2) $\varepsilon_{\max }=0.35 \%$;

(f) SA2 (3) $\varepsilon_{\max }=0.45 \%$; (g) SB1 (1) $\varepsilon_{\max }=0.25 \%$; (h) SB1 (2) $\varepsilon_{\max }=0.35 \%$; (i) SB2 (1) $\varepsilon \max =0.25 \%$;

(j) SB2 (2) $\varepsilon_{\max }=0.35 \%$; (k) SB2 (3) $\varepsilon_{\max }=0.45 \%$.

\subsection{Variation of Cyclic Stress Amplitude}

As seen in Figure 8, obtained through Figures 6 and 7 are curves about the variation of the cyclic stress amplitudes with increases to the cyclic cycles of the welding materials and steels, in which the non-dimensional parameter $\eta$ was obtained from the numbers of semi-cycles in a certain time divided by the numbers of semi-cycles at the end of the test. Each picture in Figure 8 contains three stress amplitude- $\eta$ curves that were obtained from three loading conditions with different strain amplitudes, which can be realized from Table 1 and Figure 4. Therefore, the influence of weld form, base material type, and loading mode on the damage accumulation of the welding materials will be compared and analyzed.

As shown in Figure $8 \mathrm{a}-\mathrm{f}$, the degradation of the cyclic stress amplitude is basically divided into three stages, corresponding to the three stages of crack development in a low-cycle fatigue test. The stress amplitude degenerated rapidly in the first stage, which has a number of cycles less than $20 \%$, corresponding to the initial stage of fatigue crack development. When the numbers of cycle reached about $20 \%$, the stress amplitude decreased steadily, and corresponded to the stable stage of fatigue crack development, which is the longest stage of stress amplitude degradation. Finally, the stress amplitude degenerated sharply and the specimens were fractured rapidly when the number of cycles reached about $80 \%$ or $90 \%$. Loading strain amplitude has a certain effect on the damage degradation rate. As we can see, there are three curves in each picture of Figure $8 \mathrm{a}-\mathrm{f}$, and the loading train amplitude of the curves increased in turn. It indicates that the cyclic stress amplitude increased with the increasing of the controlled strain amplitude. Moreover, the specimens with larger controlled strain amplitude degenerated faster in the failure stage. All of the above indicate that the larger the controlled loading strain amplitude, the faster the rate of damage accumulation.

The influence of type of specimens also should be discussed. As shown in Figure $8 \mathrm{~g}-\mathrm{h}$, the stress amplitude- $\eta$ curves of WA and WB welding specimens are compared at the same time. It can be concluded that the stress amplitude of the welding materials with Q235 base metal degenerated faster than that of the Q345 base metal, and the curves of WB specimens are more concentrated than those of WA specimens, indicating that the influence of the loading strain amplitude in the rate of damage accumulation is more significant for welding materials with a Q235 base steel. For the influence of the welding mode, the welded form of No. (1) specimens with the Q235 and Q345 base metal is a butt 
weld (the dotted line in Figure 8g-h), whose stress amplitudes are lower than that of the fillet weld specimens under the same working conditions. This can be attributed to the fact that the structure and welding process of the fillet welds are more complex than the butt welds, resulting in more damage accumulation than the fillet welds.

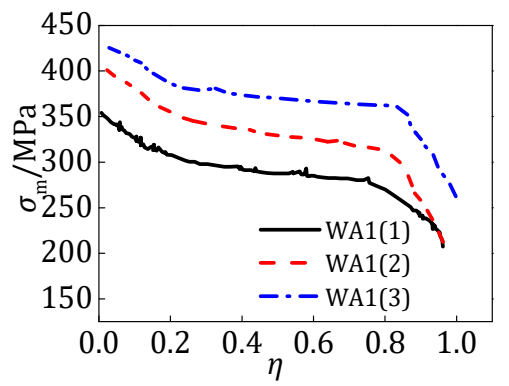

(a)

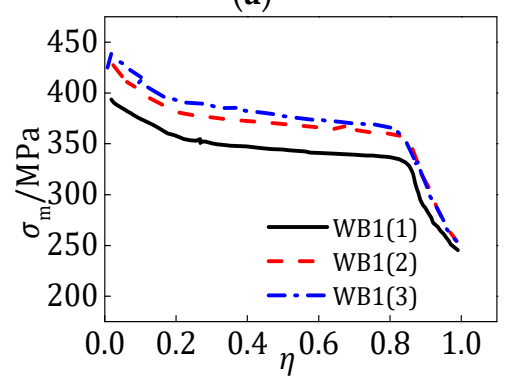

(d)

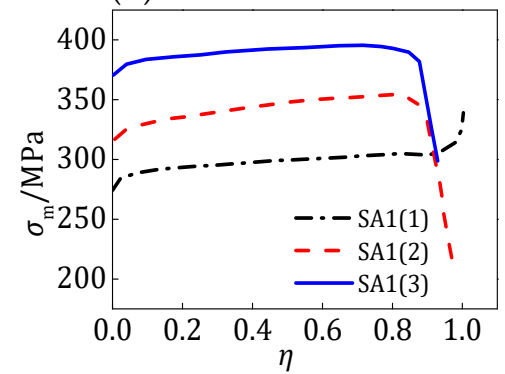

(g)

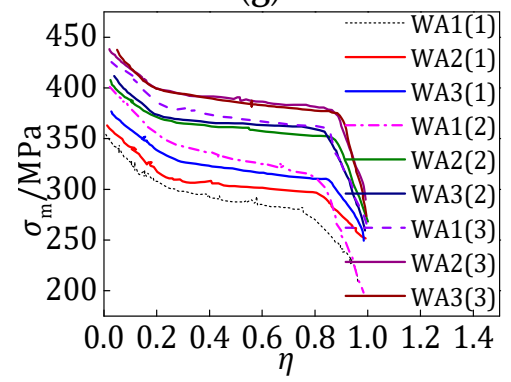

(i)

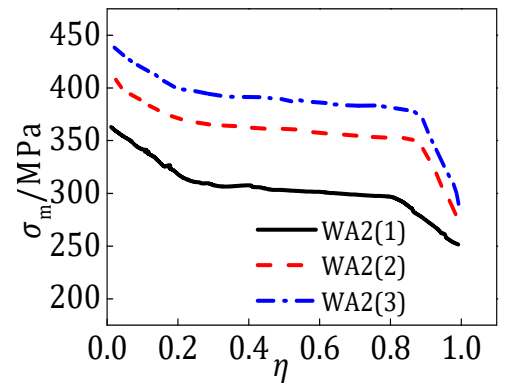

(b)

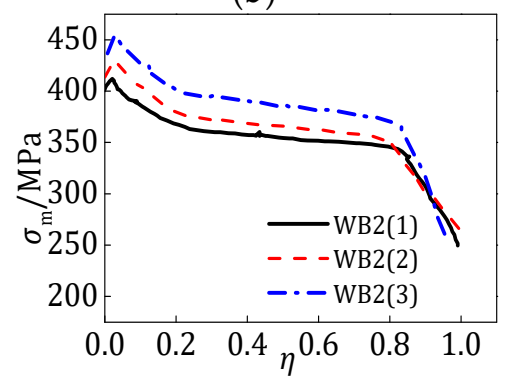

(e)

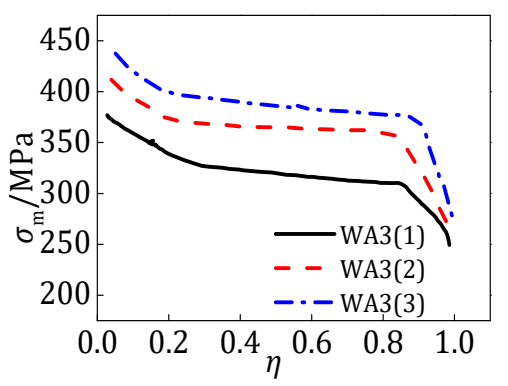

(c)

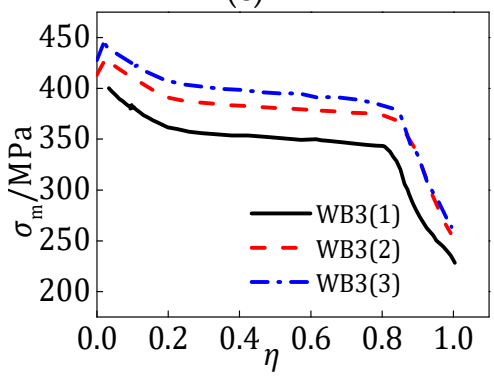

(f)

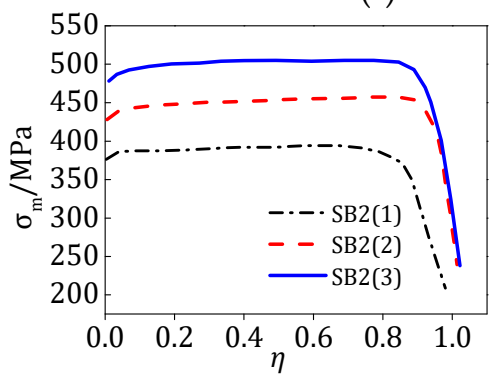

(h)

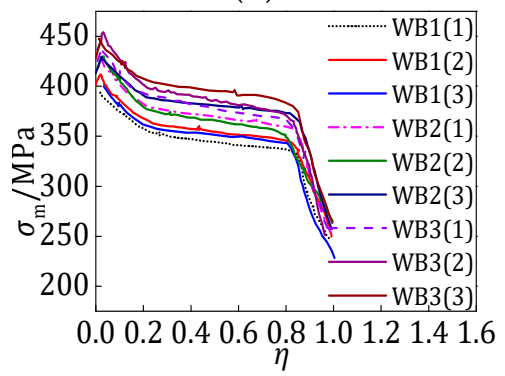

(j)

Figure 8. Stress amplitude-dimensionless $\left(\sigma_{\mathrm{m}}-\eta\right)$ half cycle of welding material and steel. (a) WA1; (b) WA2; (c) WA3; (d) WB1; (e) WB2; (f) WB3; (g) WA; (h) WB; (i) SA1; (j) SB2.

\subsection{EnergyDissipation Behavior}

Referring to the consideration of energy dissipation in the Park-Ang damage cumulative model [58], the cumulative energy dissipation is dealt with in the dimensionless method, and the energy dissipation capacity is reflected by the cumulative energy dissipation coefficient $\xi_{a}$. The expression is shown in Equation (1) [58]. $E_{u}$ is the ultimate hysteretic energy under monotonic loading, which can be calculated from the area enclosed by the stress-strain curves of monotonic tensile test and the coordinate axis. $E_{i}$ is the actual dissipated energy of the No. $i$ semi-cycle, which can be calculated 
from the area enclosed by the cyclic stress-strain hysteretic curves of cyclic loading test and the coordinate axis. Then, $\xi_{a}-\eta$ curve of welded material is depicted in Figure 9, it can be seen that the slope of the curves decreases with the increase of cyclic cycles, which means that the rate of cumulative energy dissipation decreases gradually, in other words, the enclosing area of the hysteretic loops decreases with the increase of cyclic cycles, and the energy dissipation capacity decreases gradually. It is due to the continuous damage accumulation of the welding materials under cyclic loading. In a word, the cumulative damage rule of the welding material can be discussed through cumulative energy dissipation behavior is consistent with the law of stress amplitude degradation. That is, with the continuous development of damage accumulation under cyclic loading, the amplitude of cyclic stress, unloading stiffness, and energy dissipation capacity of the welded metal, these degenerate gradually until failure occurs, and compared with the base metal, the welded metal is more prone to damage accumulation.

$$
\xi_{a}=\frac{\sum_{i=1}^{n} E_{i}}{E_{u}}
$$

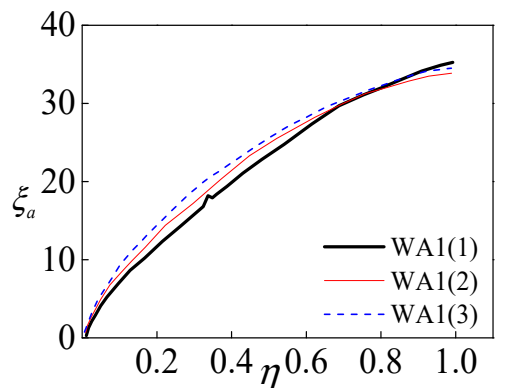

(a)

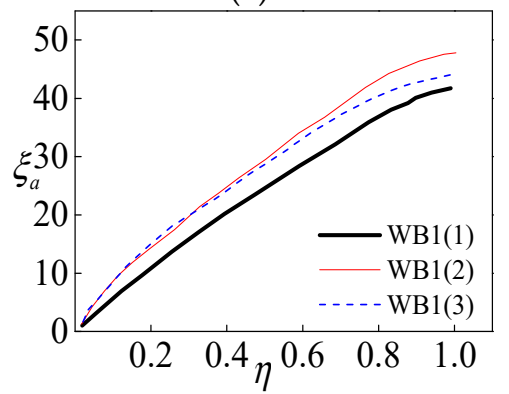

(d)

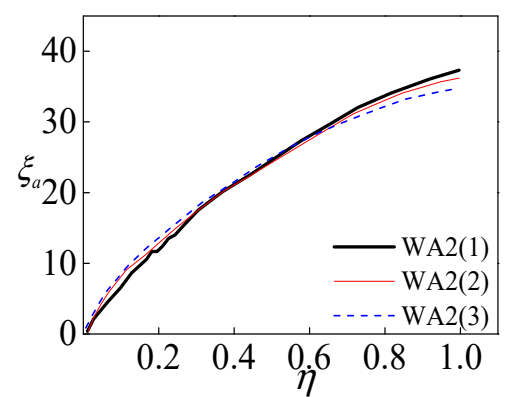

(b)

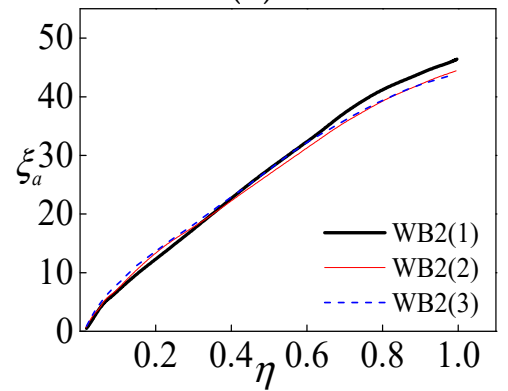

(e)

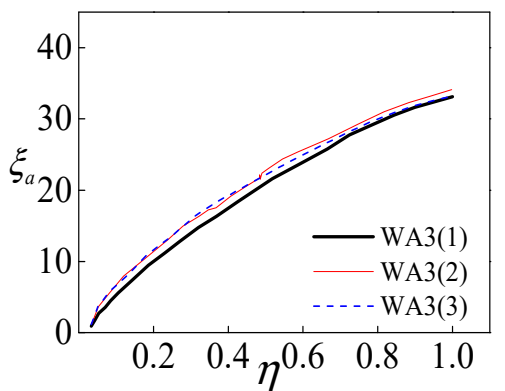

(c)

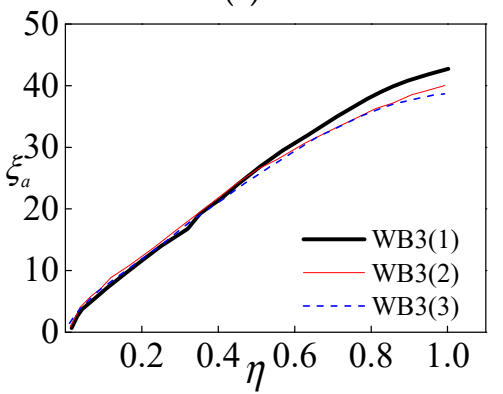

(f)

Figure 9. $\xi_{a}-\eta$ curve of welding material. (a) WA1 $1 \xi_{a}-\eta$; (b) WA2 $\xi_{a}-\eta$; (c) WA3 $\xi_{a}-\eta$; (d) WB1 $\xi_{a}-\eta$; (e) WA $2 \xi_{a}-\eta$; (f) WA $3 \xi_{a}-\eta$.

\section{An Evolution Equation of Damage Accumulation for Welding Materials}

Damage variable $D$ is used to represent the damage degree of material in damage theory [59]. Meanwhile, the experimental results show that the macroscopic mechanical behavior of the damage of the welding material can be expressed in both energy and deformation. Therefore, in order to describe the microscopic structural damage mechanism of the material in macroscopic mechanics, the evolution equation of the damage variable $D$ of the welding material under cyclic loading is established based on the experimental results. As shown in Equation (2), the Park-Ang [58] model is suitable for structural damage cumulative analysis, in which $\delta_{m}$ and $\delta_{u}$ is the maximum deformation with loading and ultimate deformation of material respectively, $\int d E$ is the cumulative dissipation of plastic energy, $F_{y} \delta_{u}$ is equivalent to the ultimate hysteretic energy under the monotonic load of perfect elastic-plastic condition.

Based on the above model, an evolution equation of damage variable $D(2)$ for calculating the cumulative damage of the welding material is established, as seen in Equation (3), in which the effects 
of plastic strain and cumulative plastic energy dissipation on the damage accumulation of the welding material are considered comprehensively. In Equation (3), $\varepsilon_{m}^{p}$ is the maximum plastic strain in cyclic process, $\varepsilon_{u}^{p}$ is the ultimate plastic strain of materials that can be obtained from the uniaxial tensile test, $E_{i}$ is the plastic deformation energy dissipation of No. $i$ semi-cycles, which is equal to the area of the hysteresis loop in numerical value, $E_{u}$ is the ultimate hysteretic energy under monotonic loading, which can be calculated from the area enclosed by the stress-strain curves of the monotonic tensile test and the coordinate axis, $\lambda$ is a parameter means the weight of cumulative plastic energy dissipation, which can be calculated by the cyclic loading test results. Compared with Equation (2), the energy part of the model in Equation (3) is no longer confined to the perfect elastic-plastic condition, and the fact that the value of damage variable $D$ is always less than or equal to 1 until fractured is ensured.

$$
\begin{gathered}
D=\frac{\delta_{m}}{\delta_{u}}+\beta \frac{\int d E}{F_{y} \delta_{u}} \\
D=(1-\lambda) \frac{\varepsilon_{m}^{p}}{\varepsilon_{u}^{p}}+\sum_{i=n_{1}}^{n} \lambda \frac{E_{i}}{E_{u}}
\end{gathered}
$$

\section{A Hysteresis Model with Damage Accumulation of Welding Materials}

\subsection{Basic Requirements of the Model}

The damage cumulative evolution law of the welding material under cyclic loading was revealed by the experimental study. That is, with the increase of cyclic loading cycles, its plastic strain will be accumulated, and the cyclic stress amplitude, stiffness and energy dissipation capacity will be degenerated with damage accumulation. The ideal elastic-plastic, bilinear or isotropic and dynamic hardening models without considering the effect of damage accumulation cannot simulate the process of plastic strain accumulation and damage degradation, for which, the hysteretic curves will only follow the isotropic or isotropic hardening path, and there is no degradation of amplitude and stiffness. For the elastic-plastic model, the hysteresis curves are basically identical while the loading amplitude remains unchanged, and the curves are linear in the hardening and plastic stage, as shown in Figure 10a, which is different from the constitutive behavior of the welded materials under cyclic large deformation, and is not consistent with the damage degradation law of welded materials under cyclic loading. Therefore, as shown in Figure 6b, a hysteretic model can used for welding material, which considering the effect of damage accumulation, should be constructed to satisfy the following requirements: (1) it can reflect the effect of damage accumulation under cyclic loading; (2) every semi-cyclic hysteretic curve calculated by the hysteretic model will change constantly, and the expression of the curve should be recursive; (3) it can reflect the nonlinear strengthening.

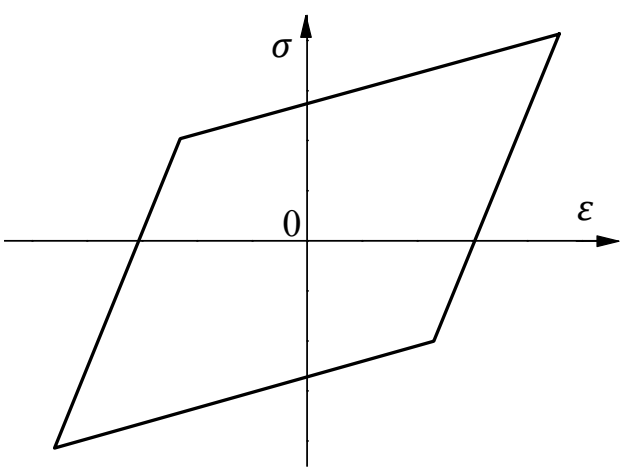

(a)

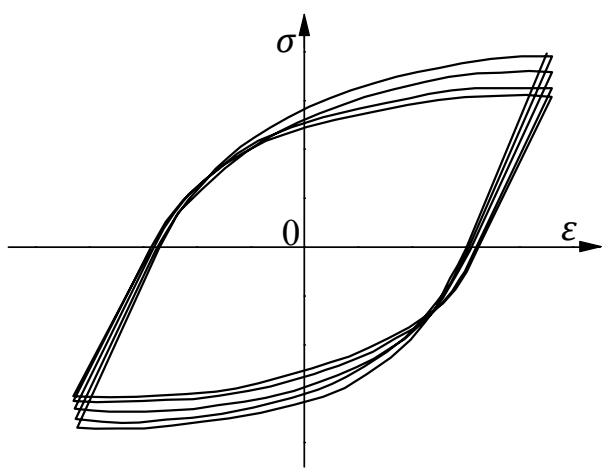

(b)

Figure 10. Hysteresis curves under different stress-strain constitutive relations. (a) Bilinear model; (b) Basic requirements of the hysteresis model. 


\subsection{Initial Loading Curve}

The expression of the initial loading curve is shown in Equation (4), which is established though the uniaxial tensile test for a welded material and the curve is depicted in Figure 11a, in which the stages named I, II, and III correspond to the formulas in Equation (4), respectively. The constitutive equation contains the effect of damage, and the parameters will be fitted by the uniaxial tensile test results obtained before the cyclic test. Figure $11 \mathrm{~b}$ is the fitting result of the WA1 specimen. And the results of the other specimens are shown in Table 4.

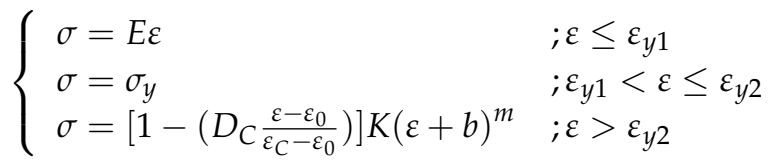

Table 4. Parameter values of initial loading curve.

\begin{tabular}{ccccccccccc}
\hline Base Metal & Welding Material & E/Gpa & $\sigma_{y} / \mathbf{M P a}$ & $K / \mathrm{Gpa}$ & $\boldsymbol{m}$ & $\varepsilon_{\mathbf{y} \mathbf{1}} / \%$ & $\varepsilon_{y_{\mathbf{2}}}\left(\varepsilon_{\mathbf{0}}\right) / \%$ & $\varepsilon_{\boldsymbol{c}} / \%$ & $\boldsymbol{b}$ & $\boldsymbol{D}_{\boldsymbol{C}} / \%$ \\
\hline \multirow{2}{*}{ Q235 } & Butt weld & 239.70 & 391.70 & 2.73 & 0.77 & 0.16 & 1.50 & 21.25 & 0.065 & 59.24 \\
& Fillet weld & 223.30 & 401.94 & 1.82 & 0.54 & 0.18 & 1.50 & 21.34 & 0.046 & 50.03 \\
\hline \multirow{2}{*}{ Q345 } & Butt weld & 247.71 & 420.07 & 2.52 & 0.65 & 0.17 & 1.70 & 17.71 & 0.052 & 57.64 \\
& Fillet weld & 241.07 & 433.92 & 2.17 & 0.60 & 0.18 & 1.70 & 16.97 & 0.044 & 53.11 \\
\hline
\end{tabular}

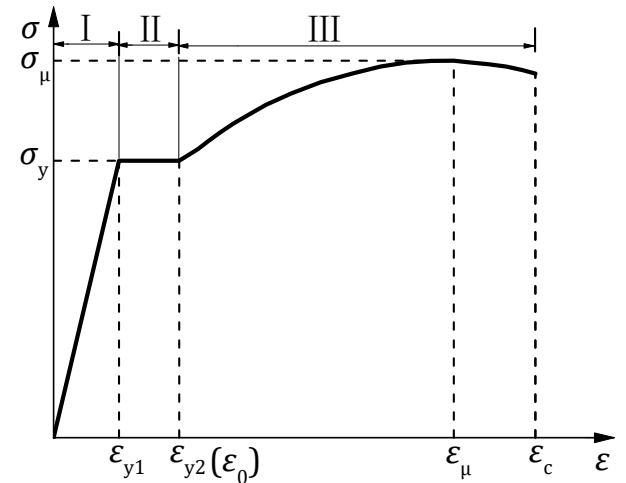

(a)

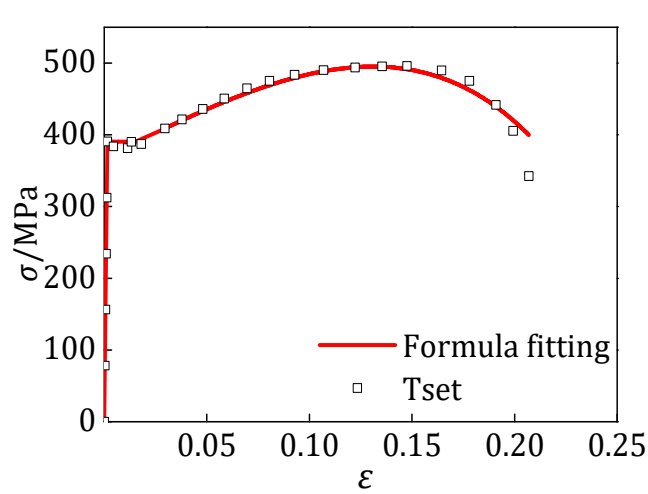

(b)

Figure 11. Fitting results of the initial loading curve. (a) The schematic diagram of the initial loading curve; (b) Fitting result of the WA1 specimen.

\subsection{Cyclic Stress-Strain Curve Based on Ramberg-Osgood Model}

The stress-strain hysteretic curves obtained from different loading strain amplitudes are placed in the same coordinate system, and the maximum and minimum stress peaks are connected to obtain the cyclic stress-strain curves, just as depicted in Figure 12, which does not represent the true stress-strain path of the welded material under cyclic loading, but is a cyclic stress-strain curve under steady state. Researches $[33,60,61]$ show that the cyclic stress-strain curves of steady-state are different from those under monotonic loading, the cyclic stress-strain curve can be described by the Ramberg-Osgood [43] model approximately, as presented in Equation (5). $E_{0}$ and $K_{0}$ are the initial elastic modulus and hardening coefficients, respectively, which can be fitted by the Low-cycle fatigue test of the welding materials. The parameters of Equation (5) are summarized in Table 5.

$$
\varepsilon= \begin{cases}\frac{\sigma}{E_{0}}+\left(\frac{\sigma}{K_{0}}\right)^{n_{0}} & ; \sigma>0 \\ \frac{\sigma}{E_{0}}-\left(\frac{-\sigma}{K_{0}}\right)^{n_{0}} & ; \sigma \leq 0\end{cases}
$$


Got the logarithm of Equation (5), just as Equation (6), then, let $y=\ln \left(\varepsilon-\frac{\sigma}{E_{0}}\right), x=\ln \sigma$, $b=-n_{0} \ln K_{0}$, Equation (6) will transform to Equation (7), thus, linear fitting can be performed.

$$
\begin{aligned}
\ln \left(\varepsilon-\frac{\sigma}{E_{0}}\right) & =n_{0}\left(\ln \sigma-\ln K_{0}\right) \\
y & =n_{0} x+b
\end{aligned}
$$

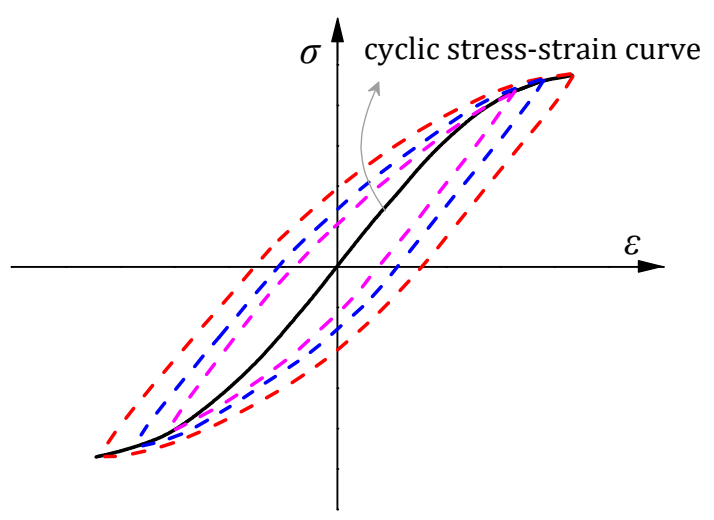

Figure 12. Schematic diagram of cyclic stress-strain curve.

Table 5. Parameters of the cyclic stress-strain curves for welding materials.

\begin{tabular}{cccccccc}
\hline \multicolumn{3}{c}{ With Q235 Base Metal } & \multicolumn{5}{c}{ With Q345 Base Metal } \\
\hline Specimens & $\boldsymbol{E}_{\mathbf{0}} / \mathrm{GPa}$ & $\boldsymbol{K}_{\mathbf{0}} / \mathbf{M P a}$ & $\boldsymbol{n}_{\mathbf{0}}$ & Specimens & $\boldsymbol{E}_{\mathbf{0}} / \mathrm{GPa}$ & $\boldsymbol{K}_{\mathbf{0}} / \mathbf{M P a}$ & $\boldsymbol{n}_{\mathbf{0}}$ \\
\hline WA1 & 239.700 & 1266 & 4.784 & WB1 & 247.710 & 953 & 8.099 \\
WA2 & 223.000 & 1331 & 5.531 & WB2 & 241.070 & 939 & 8.610 \\
WA3 & 223.000 & 1466 & 6.203 & WB3 & 241.070 & 885 & 9.272 \\
\hline
\end{tabular}

\subsection{A Model of Hysteretic Curve with Damage Accumulation}

The Ramberg-Osgood model has proven to be a good description of the cyclic stress-strain relationship of the metallic materials by many studies, and the Masing criterion shows that the stress-strain path under cyclic loading can be described by amplifying 1 time the cyclic stress-strain curve in a steady state [62-65], such as explained in Figure 13. Based on the theory, and considering the effect of the damage, the evolution equation of damage variable $D$ is introduced to construct a model of the hysteretic curve for the welding material. As shown in Figure 14, a hysteresis model with damage accumulation of welding materials is presented, in which the No. $n$ semi-cycle is shown as an example to describe the hysteresis criterion.

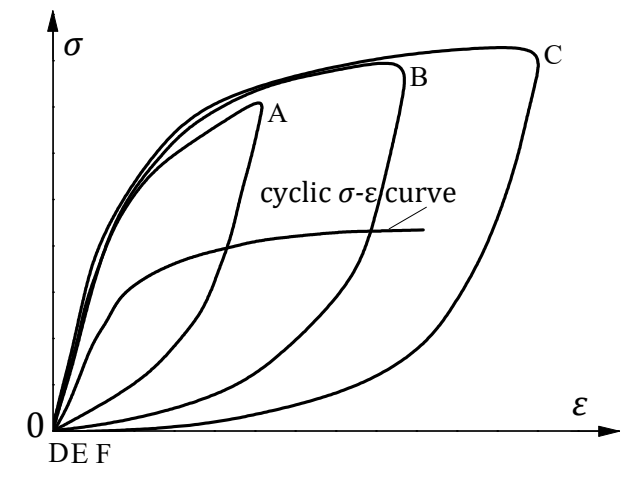

Figure 13. Masing behavior. 
Curve $A_{n}-C_{n}-B_{n}$ is the loading curve of No. $n$ semi-cycle, which is constructed by considering nonlinear loading. Point $A_{n}$ is the starting point of the $n$ semi-cycle loading curve, and $B_{n}$ is the final point of the loading curve, but is the starting point of the $n$ semi-cycle unloading curve. $\sigma_{m}^{D(n)}$ is the stress amplitude of the No. $n$ semi-cyclic stress-strain curve and the ordinate of point $B_{n}$. The stress amplitude of each semi-cycle will be degraded with damage accumulating, so $\sigma_{m}^{D(n)}$ is thought of as the damage stress amplitude, which can be calculated by Equation (8) based on damage mechanics theory, $\sigma_{m}$ is the initial stress amplitude, $D_{n}$ is the cumulative damage variable after $n$th semi-cycle, which can be calculated by Equation (3), $\eta$ and $\xi$ are the damage parameters that can be fitted by the low-cycle fatigue test results of the welding material. Curve $B_{n}-A_{n+1}$ is the unloading curve of No. $n$ semi-cycle, and the unloading process is approximately elastic. $E_{n}^{D}$ is the elastic modulus with damage accumulation, which in respect of $D_{n}$ can be calculated by Equation (9) based on damage mechanics theory and Shen [30,31]. $E_{0}$ is the original elastic modulus, $g$ and $h$ are the damage parameters like $\eta$ and $\xi$.

$$
\begin{gathered}
\sigma_{m}^{D(n)}=\left(\eta-\xi D_{n}\right) \sigma_{m} \\
E_{n}^{D}=\left(g-h D_{n}\right) E_{0}
\end{gathered}
$$

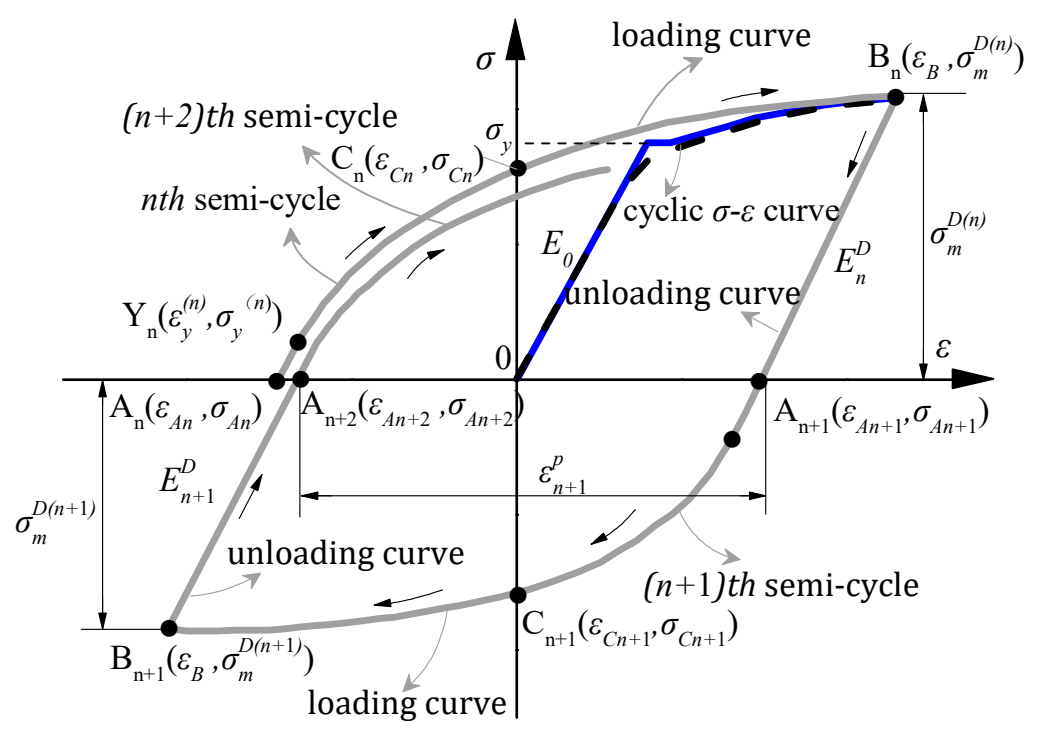

Figure 14. Hysteretic model of welding material considering cumulative damage under cyclic loading.

Overall, the hysteresis model considering damage accumulation of welding material is depicted in Figure 14, the expressions of the model are as follows:

(1) unloading curve (Linear)

$$
\begin{gathered}
\sigma_{n}=E_{n}^{D} \varepsilon_{n}+t_{n} \\
t_{n}=\left(\sigma_{m}^{D(n)}-E_{n}^{D} \varepsilon_{B}\right)
\end{gathered}
$$

In Equations (10) and (11), $\sigma_{n}$ and $\varepsilon_{n}$ are stress and strain values of point at $n$th semi-cycle curves, $t_{n}$ is the parameter for determining the shape of the curve, $\varepsilon_{B}$ is the strain amplitude.

(2) loading curve (nonlinear) 
The expression of the model is established based on the damage degenerating law, Ramberg-Osgood model and Masing behavior.

$$
\varepsilon_{n}= \begin{cases}\frac{\sigma_{n}-\sigma_{m}^{D(n)}}{E_{n}^{D}}+\left(\frac{\sigma_{n}-\sigma_{m}^{D(n)}}{K^{\prime}}\right)^{n^{\prime}}+\varepsilon_{B} & ;\left(\sigma_{n}-\sigma_{m}^{D(n)}\right)>0 \\ \frac{\sigma_{n}-\sigma_{m}^{D(n)}}{E_{n}^{D}}-\left(\frac{\sigma_{m}^{D(n)}-\sigma_{n}}{K^{\prime}}\right)^{n^{\prime}}+\varepsilon_{B} & ;\left(\sigma_{n}-\sigma_{m}^{D(n)}\right)<0\end{cases}
$$

In Equation (13), $\sigma_{m}^{D(n)}$ and $E_{n}^{D}$ are degenerated according to Formulas (10) and (11), $K^{\prime}$ and $n^{\prime}$ can be fitted by the data of the low-cycle fatigue test. Equation (13) shows that, considering the effect of damage accumulation, the stress-strain paths of each semi-cycle determined by the model do not coincide completely even in the case of constant amplitude cycling. And the unloading stiffness, bearing capacity, and energy dissipation capacity are irreversibly degraded with the increase of the number of half cycles, which is consistent with the damage accumulation law of the welding materials reflected in the test.

In conclusion, the hysteresis model with damage accumulation for welding materials is as follows:

$$
\varepsilon_{n}= \begin{cases}\frac{\sigma_{n}-\sigma_{m}^{D(n)}}{E_{n}^{D}}+\left(\frac{\sigma_{n}-\sigma_{m}^{D(n)}}{K_{n}^{D}}\right)^{n^{\prime}}+\varepsilon_{B} & ; d|\sigma| \geq 0,\left(\sigma_{n}-\sigma_{m}^{D(n)}\right) \geq 0 \\ \frac{\sigma_{n}-t_{n}}{E_{n}^{D}} & ; d|\sigma| 0 \\ \frac{\sigma_{n}-\sigma_{m}^{D(n)}}{E_{n}^{D}}-\left(\frac{\sigma_{m}^{D(n)}-\sigma_{n}}{K_{n}^{D}}\right)^{n^{\prime}}+\varepsilon_{B} & ; d|\sigma| \geq 0,\left(\sigma_{n}-\sigma_{m}^{D(n)}\right) \leq 0\end{cases}
$$

As shown in Figure 14, the hysteresis model can be calculated by Equations (3), (8), (9) and (13), and the effect of damage accumulation is considered to start from the second semi-cycle. Damage degradation is considered by introducing the evolution equation of the damage variable $D$. The realization process of the hysteresis criterion is: the initial stress amplitude under cyclic loading is calculated by the cyclic stress-strain curve and the initial loading curve $\rightarrow$ the damage variable $D_{n}$ of each semi-cycle is calculated by Equation $(3) \rightarrow$ the stress amplitude $\sigma_{m}^{D(n)}$ and the elastic modulus $E_{n}^{D}$ are calculated by Equations (8) and (9) $\rightarrow$ the hysteresis curve of the $n$th semi-cycle can be obtained by Equation (13) $\rightarrow$ then calculate the $(n+1)$ th semi-cycle, and so on.

\subsection{Parameter Fitting of the Model}

\subsubsection{The Parameter $\lambda$ of EvolutionEquation of Damage Accumulation}

The cumulative damage variable $D$ will be valued 1 when the specimen is destroyed, and calculate the maximum plastic strain $\varepsilon_{m}^{p}$ and the cumulative plastic energy dissipation in the cyclic process, then the parameter $\lambda$ can be obtained use Equation (3), so the value of $\lambda$ can fitaccording to Equation (14) by the test data, and the fitting results are presented in Table 6 .

$$
\lambda=\frac{1-\frac{\varepsilon_{m}^{p}}{\varepsilon_{u}^{p}}}{\sum_{n_{1}}^{n} \frac{E_{i}}{E_{m}}-\frac{\varepsilon_{m}^{p}}{\varepsilon_{u}^{p}}}
$$


Table 6. Values of Parameter $\lambda$.

\begin{tabular}{ccccccc}
\hline \multirow{2}{*}{ Specimens } & \multicolumn{2}{c}{ Welding Material of Q235 Steel } & \multicolumn{2}{c}{ Welding Material of Q345 Steel } \\
\cline { 2 - 7 } & Butt Weld & \multicolumn{2}{c}{ Fillet Weld } & Butt Weld & \multicolumn{2}{c}{ Fillet Weld } \\
\cline { 2 - 7 } & WA1 & WA2 & WA3 & WB1 & WB2 & WB3 \\
\hline$(1)$ & 0.02529 & 0.02609 & 0.02871 & 0.02311 & 0.02156 & 0.02176 \\
$(2)$ & 0.02233 & 0.02538 & 0.02613 & 0.01905 & 0.01909 & 0.02433 \\
$(3)$ & 0.02905 & 0.03043 & 0.03280 & 0.02071 & 0.02326 & 0.02230 \\
Model Parameters & 0.0256 & 0.0273 & 0.0294 & 0.0209 & 0.02130 & 0.0227 \\
\hline
\end{tabular}

5.5.2. The Parameters $\eta, \xi, g, h, K^{\prime}$ and $n^{\prime}$

(1) Damage Parameters $\eta, \xi, g, h$

The parameters can be fitted according to Equations (8) and (9) by the results of low-cycle fatigue test. Equations (8) and (9) can be transformed into Equations (15) and (16), and the curves of $\frac{\sigma_{m}^{D(n)}}{\sigma_{m}}-D_{n}$ and $\frac{E_{n}^{D}}{E_{0}}-D_{n}$ of WB1(2) are presented in Figure 15 (an example). Therefore, the parameters can be fitted according to Figure 15, the values of the parameters of all welding specimens are summarized in Tables 7 and 8 .

$$
\begin{gathered}
\frac{E_{n}^{D}}{E_{0}}=g-h D_{n} \\
\frac{\sigma_{m}^{D(n)}}{\sigma_{m}}=\eta-\xi D_{n}
\end{gathered}
$$

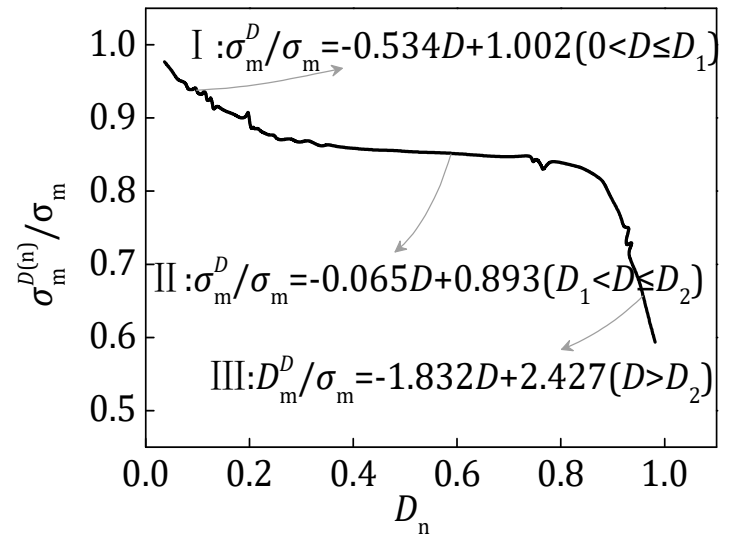

(a)

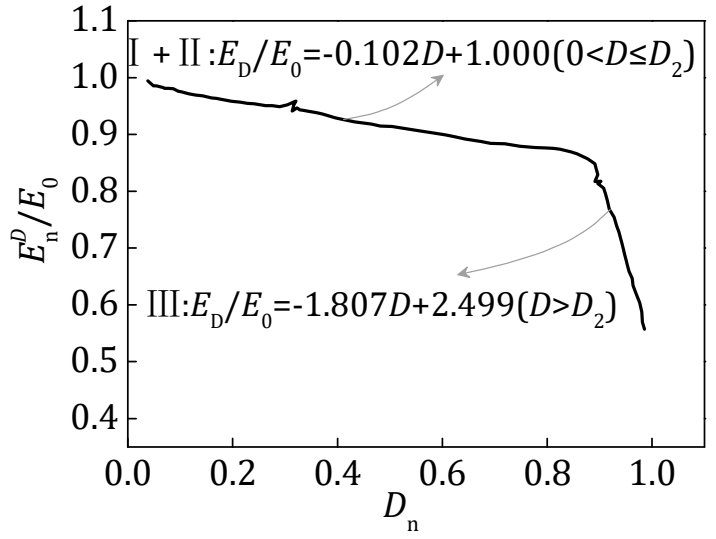

(b)

Figure 15. Parameter fitting of WB1 (2). (a) Curve $\frac{\sigma_{m}^{D(n)}}{\sigma_{m}}-D_{n} ;(\mathbf{b})$ Curve $\frac{E_{n}^{D}}{E_{0}}-D_{n}$. 
Table 7. Values of parameters $\eta, \xi$.

\begin{tabular}{|c|c|c|c|c|c|c|c|c|c|}
\hline \multirow{2}{*}{\multicolumn{2}{|c|}{ Specimens }} & \multicolumn{3}{|c|}{ I } & \multicolumn{3}{|c|}{ II } & \multicolumn{2}{|c|}{ III } \\
\hline & & $\xi_{1}$ & $\eta_{1}$ & $D_{1}$ & $\xi_{2}$ & $\eta_{2}$ & $D_{2}$ & $\xi_{3}$ & $\eta_{3}$ \\
\hline \multirow{4}{*}{$\begin{array}{l}\text { Butt weld of } \\
\text { Q235 steel }\end{array}$} & WA1(1) & 0.509 & 0.961 & 0.228 & 0.099 & 0.873 & 0.897 & 1.799 & 2.350 \\
\hline & WA1(2) & 0.475 & 0.998 & 0.239 & 0.105 & 0.875 & 0.866 & 1.879 & 2.355 \\
\hline & WA1(3) & 0.485 & 1.001 & 0.231 & 0.087 & 0.897 & 0.860 & 1.770 & 2.362 \\
\hline & Model Parameters & 0.489 & 0.986 & 0.233 & 0.097 & 0.882 & 0.874 & 1.816 & 2.356 \\
\hline \multirow{4}{*}{$\begin{array}{l}\text { Left fillet weld of } \\
\text { Q235 steel }\end{array}$} & WA2(1) & 0.530 & 1.001 & 0.247 & 0.057 & 0.858 & 0.883 & 1.191 & 1.871 \\
\hline & WA2(2) & 0.455 & 0.997 & 0.241 & 0.058 & 0.901 & 0.886 & 2.158 & 2.790 \\
\hline & WA2(3) & 0.456 & 0.998 & 0.226 & 0.059 & 0.899 & 0.859 & 2.157 & 2.788 \\
\hline & Model Parameters & 0.480 & 0.999 & 0.238 & 0.058 & 0.886 & 0.876 & 1.825 & 2.483 \\
\hline \multirow{4}{*}{$\begin{array}{l}\text { Right fillet weld of } \\
\text { Q235 steel }\end{array}$} & WA3(1) & 0.445 & 1.002 & 0.251 & 0.086 & 0.887 & 0.863 & 1.167 & 1.843 \\
\hline & WA3(2) & 0.500 & 1.000 & 0.243 & 0.045 & 0.889 & 0.858 & 2.078 & 2.678 \\
\hline & WA3(3) & 0.525 & 0.999 & 0.229 & 0.077 & 0.896 & 0.886 & 1.996 & 2.675 \\
\hline & Model Parameters & 0.490 & 1.000 & 0.241 & 0.069 & 0.891 & 0.869 & 1.747 & 2.399 \\
\hline \multirow{4}{*}{$\begin{array}{l}\text { Butt weld of } \\
\text { Q345 steel }\end{array}$} & WB1(1) & 0.468 & 0.999 & 0.235 & 0.058 & 0.902 & 0.899 & 2.551 & 3.151 \\
\hline & WB1(2) & 0.534 & 1.002 & 0.228 & 0.065 & 0.893 & 0.869 & 1.832 & 2.427 \\
\hline & WB1(3) & 0.508 & 0.989 & 0.236 & 0.075 & 0.887 & 0.889 & 2.235 & 2.912 \\
\hline & Model Parameters & 0.503 & 0.997 & 0.233 & 0.066 & 0.894 & 0.885 & 2.206 & 2.830 \\
\hline \multirow{4}{*}{$\begin{array}{l}\text { Left fillet weld of } \\
\text { Q345 steel }\end{array}$} & WB2(1) & 0.535 & 0.998 & 0.233 & 0.068 & 0.889 & 0.865 & 1.622 & 2.233 \\
\hline & WB2(2) & 0.625 & 1.002 & 0.241 & 0.077 & 0.868 & 0.887 & 1.620 & 2.237 \\
\hline & WB2(3) & 0.612 & 1.000 & 0.231 & 0.095 & 0.881 & 0.859 & 1.634 & 2.210 \\
\hline & Model Parameters & 0.592 & 1.000 & 0.235 & 0.080 & 0.879 & 0.865 & 1.625 & 2.227 \\
\hline \multirow{4}{*}{$\begin{array}{l}\text { Right fillet weld of } \\
\text { Q345 steel }\end{array}$} & WB3(1) & 0.505 & 0.998 & 0.219 & 0.064 & 0.902 & 0.875 & 2.279 & 2.841 \\
\hline & WB3(2) & 0.446 & 0.997 & 0.241 & 0.048 & 0.901 & 0.887 & 2.587 & 3.153 \\
\hline & WB3(3) & 0.455 & 0.998 & 0.246 & 0.063 & 0.902 & 0.878 & 2.284 & 2.854 \\
\hline & Model Parameters & 0.469 & 0.998 & 0.235 & 0.058 & 0.902 & 0.880 & 2.383 & 2.949 \\
\hline
\end{tabular}

Table 8. Values of parameters $g, h$.

\begin{tabular}{ccccccc}
\hline \multirow{2}{*}{ Specimens } & & \multicolumn{3}{c}{ I + II } & \multicolumn{3}{c}{ III } \\
\cline { 3 - 7 } & & $\boldsymbol{h}_{\mathbf{2}}$ & $\boldsymbol{g}_{\mathbf{2}}$ & $\boldsymbol{D}_{\mathbf{2}}$ & $\boldsymbol{h}_{\mathbf{3}}$ & $\boldsymbol{g}_{3}$ \\
\hline \multirow{3}{*}{ Butt weld of } & WA1(1) & 0.045 & 0.991 & 0.889 & 2.083 & 2.466 \\
Q235 steel & WA1(2) & 0.024 & 0.982 & 0.881 & 1.694 & 2.433 \\
& WA1(3) & 0.024 & 0.989 & 0.879 & 1.668 & 2.453 \\
& Model Parameters & 0.031 & 0.987 & 0.883 & 1.815 & 2.446 \\
\hline \multirow{2}{*}{ Left fillet weld of } & WA2(1) & 0.020 & 0.997 & 0.875 & 1.751 & 2.553 \\
Q235 steel & WA2(2) & 0.021 & 0.998 & 0.882 & 1.751 & 2.503 \\
& WA2(3) & 0.020 & 0.997 & 0.879 & 1.709 & 2.513 \\
& Model Parameters & 0.020 & 0.997 & 0.879 & 1.737 & 2.523 \\
\hline \multirow{2}{*}{ Right fillet weld of } & WA3(1) & 0.056 & 1.000 & 0.887 & 1.345 & 2.134 \\
Q235 steel & WA3(2) & 0.020 & 0.997 & 0.886 & 1.384 & 2.196 \\
& WA3(3) & 0.113 & 1.000 & 0.886 & 0.981 & 1.796 \\
Butt weld of & Model Parameters & 0.063 & 0.999 & 0.886 & 1.225 & 2.044 \\
Q345 steel & WB1(1) & 0.109 & 0.999 & 0.890 & 1.519 & 2.269 \\
& WB1(2) & 0.111 & 1.000 & 0.882 & 1.807 & 2.499 \\
& WB1(3) & 0.103 & 1.002 & 0.886 & 1.445 & 2.196 \\
Left fillet weld of & Model Parameters & 0.107 & 1.000 & 0.886 & 1.509 & 2.321 \\
Q345 steel & WB2(1) & 0.113 & 0.997 & 0.879 & 1.005 & 1.825 \\
& WB2(2) & 0.094 & 0.999 & 0.881 & 1.083 & 1.878 \\
& WB2(3) & 0.104 & 1.001 & 0.877 & 1.054 & 1.883 \\
Right fillet weld of & Model Parameters & 0.104 & 0.999 & 0.879 & 1.047 & 1.862 \\
Q345 steel & WB3(1) & 0.083 & 0.999 & 0.857 & 1.198 & 1.956 \\
& WB3(2) & 0.057 & 1.000 & 0.887 & 2.365 & 3.043 \\
& WB3(3) & 0.089 & 0.999 & 0.890 & 1.789 & 2.513 \\
& Model Parameters & 0.076 & 0.999 & 0.878 & 1.784 & 2.504 \\
\hline
\end{tabular}

(2) $\quad K^{\prime}$ and $n^{\prime}$

The Parameters $K^{\prime}$ and $n^{\prime}$ can be fitted through Equation (12) and the test results, which are presented in Table 9. 
Table 9. Values of parameters $K^{\prime}$ and $n^{\prime}$.

\begin{tabular}{|c|c|c|c|c|}
\hline Spe & mens & $\varepsilon_{\mathrm{B}} / \%$ & $K^{\prime}$ & $n^{\prime}$ \\
\hline \multirow{4}{*}{ WA1 } & WA1(1) & 0.25 & $2.26 \times 10^{7}$ & 0.546 \\
\hline & WA1(2) & 0.35 & $2.65 \times 10^{7}$ & 0.499 \\
\hline & WA1(3) & 0.45 & $3.05 \times 10^{7}$ & 0.459 \\
\hline & \multicolumn{2}{|c|}{ Model Parameters } & $K^{\prime}=3.95 \times 10^{9} \varepsilon_{B}+1.27 \times 10^{7}$ & $n^{\prime}=-43.5 \varepsilon_{B}+0.654$ \\
\hline \multirow{4}{*}{ WA2 } & WA2(1) & 0.25 & $2.23 \times 10^{7}$ & 0.547 \\
\hline & WA2(2) & 0.35 & $2.64 \times 10^{7}$ & 0.504 \\
\hline & WA2(3) & 0.45 & $3.05 \times 10^{7}$ & 0.461 \\
\hline & \multicolumn{2}{|c|}{ Model Parameters } & $K^{\prime}=4.10 \times 10^{9} \varepsilon_{B}+1.21 \times 10^{7}$ & $n^{\prime}=-43.0 \varepsilon_{B}+0.655$ \\
\hline \multirow{4}{*}{ WA3 } & WA3(1) & 0.25 & $2.24 \times 10^{7}$ & 0.546 \\
\hline & WA3(2) & 0.35 & $2.64 \times 10^{7}$ & 0.505 \\
\hline & WA3(3) & 0.45 & $3.04 \times 10^{7}$ & 0.464 \\
\hline & \multicolumn{2}{|c|}{ Model Parameters } & $K^{\prime}=4.00 \times 10^{9} \varepsilon_{B}+1.24 \times 10^{7}$ & $n^{\prime}=-41.0 \varepsilon_{B}+0.649$ \\
\hline \multirow{4}{*}{ WB1 } & WB1(1) & 0.25 & $1.40 \times 10^{7}$ & 0.567 \\
\hline & WB1(2) & 0.35 & $1.63 \times 10^{7}$ & 0.521 \\
\hline & WB1(3) & 0.45 & $1.86 \times 10^{7}$ & 0.475 \\
\hline & \multicolumn{2}{|c|}{ Model Parameters } & $K^{\prime}=2.30 \times 10^{9} \varepsilon_{B}+8.25 \times 10^{6}$ & $n^{\prime}=-46.0 \varepsilon_{B}+0.628$ \\
\hline \multirow{4}{*}{ WB2 } & WB2(1) & 0.25 & $1.41 \times 10^{7}$ & 0.566 \\
\hline & WB2(2) & 0.35 & $1.63 \times 10^{7}$ & 0.521 \\
\hline & WB2(3) & 0.45 & $1.85 \times 10^{7}$ & 0.476 \\
\hline & \multicolumn{2}{|c|}{ Model Parameters } & $K^{\prime}=2.25 \times 10^{9} \varepsilon_{B}+8.46 \times 10^{6}$ & $n^{\prime}=-45.0 \varepsilon_{B}+0.679$ \\
\hline \multirow{4}{*}{ WB3 } & WB3(1) & 0.25 & $1.40 \times 10^{7}$ & 0.566 \\
\hline & WB3(2) & 0.35 & $1.64 \times 10^{7}$ & 0.520 \\
\hline & WB3(3) & 0.45 & $1.86 \times 10^{7}$ & 0.475 \\
\hline & \multicolumn{2}{|c|}{ Model Parameters } & $K^{\prime}=2.30 \times 10^{9} \varepsilon_{B}+8.28 \times 10^{6}$ & $n^{\prime}=-45.5 \varepsilon_{B}+0.680$ \\
\hline
\end{tabular}

\subsection{Comparison between the Test Results and Results Calculated by the Proposal Model}

The stress-strain hysteresis curves of the welded specimens are calculated by using the hysteresis model and considering the damage accumulation, constructed by this paper (Equation (13)). The results are compared with the experimental results, as shown in Figure 16, which contain the comparison results of any six semi-cycles referred to as twenty, forty, and eighty percent of the approximate cyclic life of each specimen. It is shown that the calculated results of the model agree well with the experimental curves. The comparison indicates that the model has a good applicability. It can be seen that the amplitude of cyclic stress, elastic modulus, and hysteretic energy decrease with the increase of cyclic cycles under the same loading condition, which is consistent with the experimental results. It shows that the damage accumulation evolution law of the welding materials can be reflected effectively by the hysteretic model considering the damage accumulation.

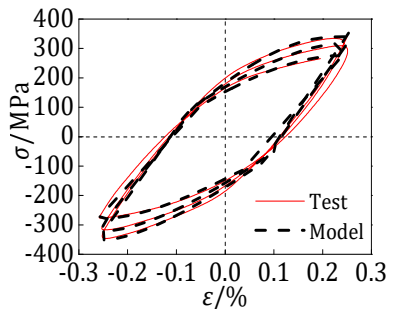

(a)

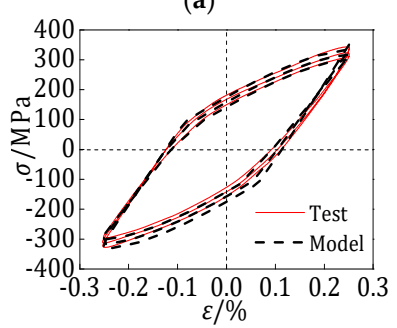

(d)

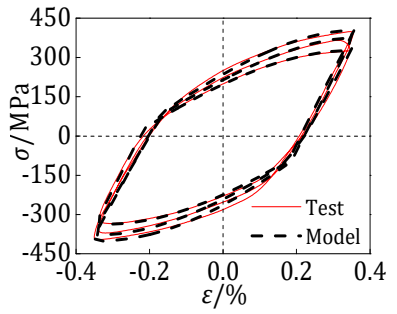

(b)

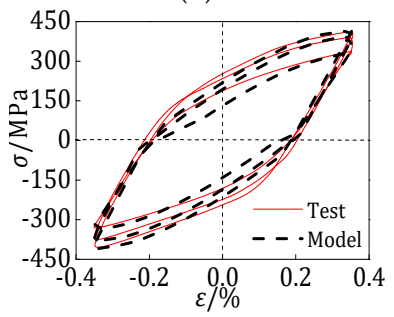

$(\mathbf{e})$

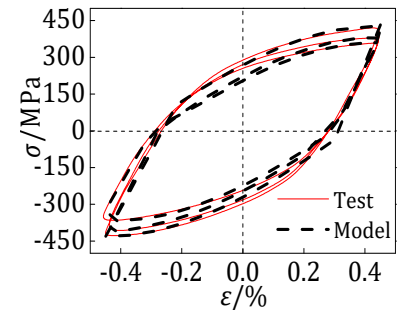

(c)

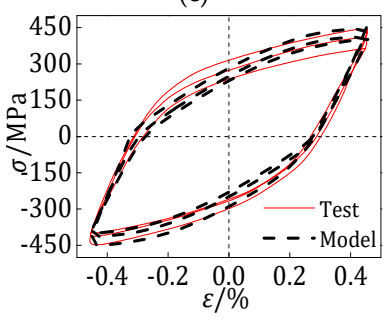

(f)

Figure 16. Cont. 


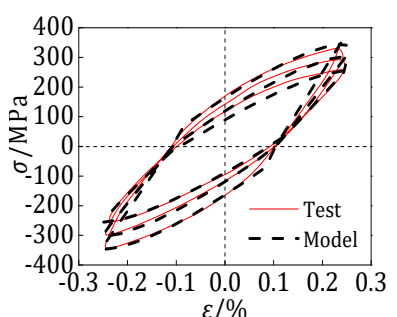

(g)

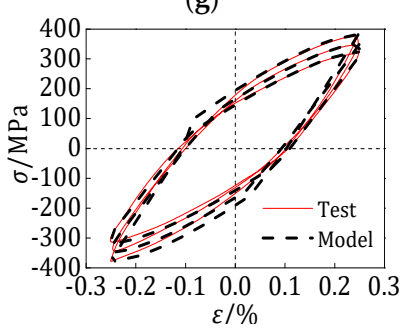

(j)

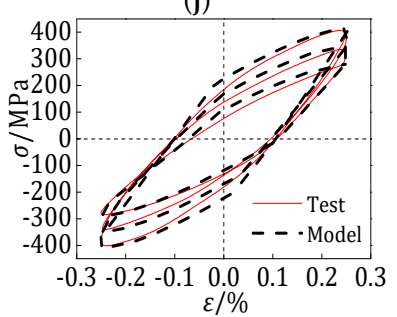

(m)

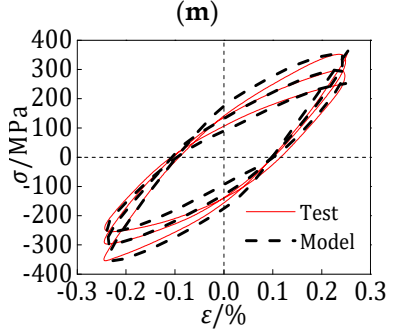

(p)

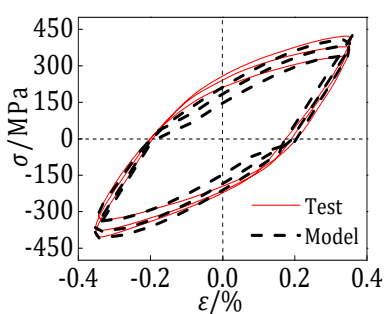

(h)

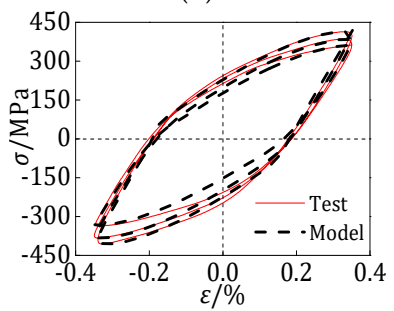

(k)

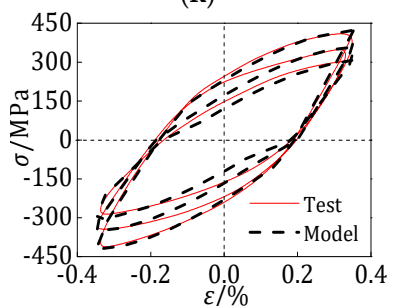

(n)

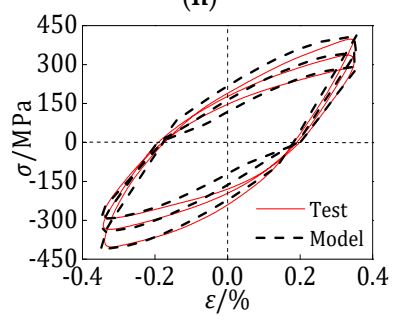

(q)

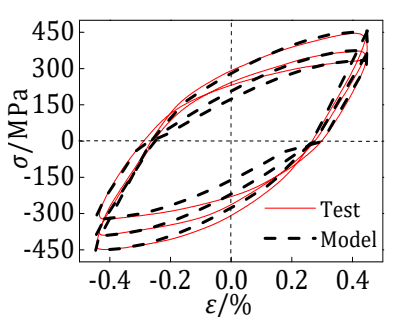

(i)

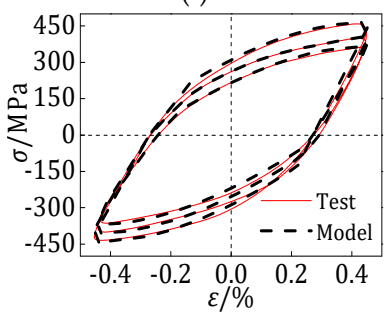

(1)

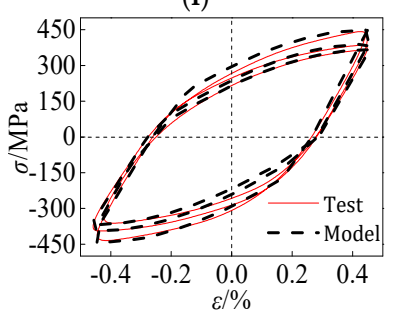

(o)

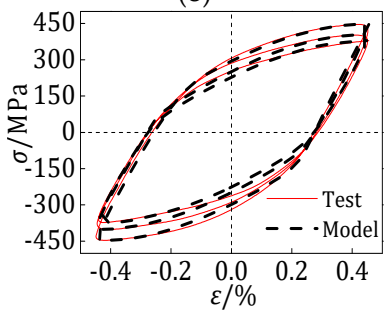

(r)

Figure 16. Comparison of hysteretic curves calculated from welding hysteresis models and test results.(a) WA1(1) $\sigma-\varepsilon$; (b) WA1(2) $\sigma-\varepsilon$; (c) WA1(3) $\sigma-\varepsilon$; (d) WA2(1) $\sigma-\varepsilon$; (e) WA2(2) $\sigma-\varepsilon$; (f) WA2(3) $\sigma-\varepsilon$; (g) WA3(1) $\sigma-\varepsilon$; (h) WA3(2) $\sigma-\varepsilon$; (i) WA3(3) $\sigma-\varepsilon$; (j) WB1(1) $\sigma-\varepsilon$; (k) WB1(2) $\sigma-\varepsilon$; (1) WB1(3) $\sigma-\varepsilon$; (m) WB2(1) $\sigma-\varepsilon ;(\mathbf{n}) \mathrm{WB} 2(2) \sigma-\varepsilon ;$ (o) WB2(3) $\sigma-\varepsilon ;$ (p) WB3(1) $\sigma-\varepsilon$; (q) WB3(2) $\sigma-\varepsilon ;(\mathbf{r}) \mathrm{WB} 3(3) \sigma-\varepsilon$.

\section{Conclusions}

In this research program, low-cycle fatigue experimental studies of welding material and steel welded joints in steel tubular truss structures were conducted under different loading conditions. The cyclic characteristics, variation of cyclic stress amplitude, and energy dissipation capacity were thoroughly discussed, with a focus on the law of damage accumulation of the welding material. Then, an evolution equation of damage accumulation for the welding material was obtained, and a hysteresismodel with damage accumulation was constructed. Based on this research of experiment and theory, the following conclusions can be drawn:

(1) The cumulative damage process of welding materials can be divided into three stages, which are presented as the stage of crack initiation, the stage of crack propagation, and the stage the specimenis fractured, and when the specimensare destroyed along the maximum main crack.

(2) As the imposed displacement cycles increased, the cyclic softening behavior of the welding materials of the welded joints in a tubular truss structureis apparent, and the steel hardening behavior is shown. Furthermore, with the increase of cyclic cycles, the effect of damage accumulation on the welding materials is obvious, that is, the cyclic stress amplitude, unloading 
stiffness, and energy dissipation capacity of the weldingmaterials degenerate gradually. Furthermore, the larger the controlled loading strain amplitude, the faster the rate of damage accumulation. The amplitude of the loading strain has a greater effect on the welding material of base metal Q235 than that of base metal Q345.

(3) Based on the test results and Park-Ang model, an evolutionequation of damage accumulation for welding materials is established considering both energy and deformation comprehensively, in which the energy part is no longer confined to the perfect elastic-plastic condition. Then, the value of parameter $\lambda$ is fitted by the test data.

(4) It is revealed by the experimental research that the cyclic characteristic and constitutive behavior of the welding material is quite different from the base metal, and the constitutive model used for monotonic loading cannot simulate the damage degradation behavior of the welding materials under cyclic loading. Therefore, a hysteresismodel with damage accumulation of welding materials is constructed based on the Ramberg-Osgood model and the experimental results, which includedthe initial loading curve, cyclic stress-strain curve, and a model of the hysteretic curve. The model can reveal the effects of damage accumulation and the nonlinear constitutive relation of the plasticstage.

(5) The damage parameters and model parameters $\eta, \xi, g, h, K^{\prime}$ and $n^{\prime}$ are fitted by the test results. The hysteretic curves calculated by the hysteretic model are compared with the test results, which show that the model has good applicability and the cumulative damage evolution law of the welding materials reflected by the model is basically consistent with the test results.

Author Contributions: W.Y. designed the experiments. Y.S. and P.C. performed the experiments. Y.S. and W.Y. analyzed the data and wrote the paper.

Funding: This research was supported in part by The National Natural Science Foundation of China under Grant 51468054 and in part by the Funding Project of First-Class Discipline Construction of Universities in Ningxia (Domestic First-Class Discipline Construction) under Grant NXYLXK2017A03.

Conflicts of Interest: The authors declare no conflict of interest.

\section{References}

1. Wardenier, J.; Packer, J.A.; Zhao, X.L.; Vegte, G.J.V.D. Hollow Sections in Structural Applications; Bouwen Met Staal: Rotterdam, The Netherlands, 2010.

2. Khademi, F. Load Rating of Railway Bridges by Analysis and Testing. Master's Thesis, Illinois Institute of Technology, Chicago, IL, USA, 2015.

3. Khademi, F. Enhancing Load Rating of Railway Truss Bridges through a Hybrid Structural Analysis and instrumentation Procedure. Ph.D. Thesis, Illinois Institute of Technology, Chicago, IL, USA, 2017.

4. Chen, Y.; Feng, R.; Gao, S.W. Experimental study of concrete-filled multiplanar circular hollow section tubular trusses. Thin-Walled Struct. 2015, 94, 199-213. [CrossRef]

5. Cui, C.; Zhang, Q.H.; Bao, Y.; Kang, J.P.; Bu, Y.Z. Fatigue performance and evaluation of welded joints in steel truss bridges. J. Constr. Steel Res. 2018, 148, 450-456. [CrossRef]

6. Gillman, A.; Fuchi, K.; Buskohl, P.R. Truss-based nonlinear mechanical analysis for origami structures exhibiting bifurcation and limit point instabilities. Int. J. Solids Struct. 2018, 147, 80-93. [CrossRef]

7. Huang, W.J.; Fenu, L.G.; Chen, B.C.; Briseghella, B. Experimental study on joint resistance and failure modes of concrete filled steel tubular (cfst) truss girders. J. Constr. Steel Res. 2018, 141, 241-250. [CrossRef]

8. Ozyurt, E.; Wang, Y.C. Effects of non-uniform temperature distribution on critical member temperature of steel tubular truss. Eng. Struct. 2016, 116, 95-106. [CrossRef]

9. Tiainen, T.; Mela, K.; Jokinen, T.; Heinisuo, M. The effect of steel grade on weight and cost of warren-type welded tubular trusses. Proc. Inst. Civ. Eng. Struct. Build. 2017, 170, 855-873. [CrossRef]

10. Van Der Kooi, K.; Hoult, N.A.; Le, H. Monitoring an in-service railway bridge with a distributed fiber optic strain sensing system. J. Bridge Eng. 2018, 23, 05018007. [CrossRef]

11. Zhou, W.; Chen, Y.; Wang, K.; Han, S.; Galarza, F.P. Experimental research on circular concrete filled stainless steel tubular truss. Thin-Walled Struct. 2017, 117, 224-238. [CrossRef] 
12. Yang, W.W.; Wang, X.L.; Wang, D.D. Design of long-span and wave-shaped steel canopy structure of ningxia helan mountain stadium. Adv. Mater. Res. 2011, 243-249, 72-78. [CrossRef]

13. Cui, W.; Wang, F. Damage Accumulation. In Encyclopedia of Tribology, 2013 Edition; Wang, Q.J., Chung, Y.-W., Eds.; Springer: Boston, MA, USA, 2013; pp. 706-709.

14. Diel, S.; Huber, O. A continuum damage mechanics model for the static and cyclic fatigue of cellular composites. Materials 2017, 10, 951. [CrossRef] [PubMed]

15. Lian, J.H.; Jia, X.X.; Munstermann, S.; Bleck, W. A generalized damage model accounting for instability and ductile fracture for sheet metals. Key Eng. Mater. 2014, 611-612, 106-110. [CrossRef]

16. Möller, B.; Baumgartner, J.; Wagener, R.; Kaufmann, H.; Melz, T. Low cycle fatigue life assessment of welded high-strength structural steels based on nominal and local design concepts. Int. J. Fatigue 2017, 101, 192-208. [CrossRef]

17. Nie, G.B.; Fan, F.; Zhi, X.D. A constitutive model for circular steel pipe by spatial hysteretic test. Adv. Struct. Eng. 2012, 15, 1279-1290. [CrossRef]

18. Rong, J.; Kyriakides, S. Ratcheting, wrinkling and collapse of tubes under axial cycling. Int. J. Solids Struct. 2009, 46, 2856-2870.

19. Whittaker, M.T.; Wilshire, B. Creep and creep fracture of 2.25cr-1.6w steels (grade 23). Mater. Sci. Eng. A 2010, 527, 4932-4938. [CrossRef]

20. Du, G.F.; Huo, L.S.; Kong, Q.Z.; Song, G.B. Damage detection of pipeline multiple cracks using piezoceramic transducers. J. Vibroeng. 2016, 18, 2828-2838. [CrossRef]

21. Feng, Q.; Kong, Q.Z.; Song, G.B. Damage detection of concrete piles subject to typical damage types based on stress wave measurement using embedded smart aggregates transducers. Measurement 2016, 88, 345-352. [CrossRef]

22. Feng, Q.; Xiao, H.; Kong, Q.Z.; Liang, Y.B.; Song, G.B. Damage detection of concrete piles subject to typical damages using piezoceramic based passive sensing approach. J. Vibroeng. 2016, 18, 801-812.

23. Ling, Y.B.; Li, D.S.; Song, G.B.; Zhan, C. Damage detection of shear buildings through structural mass-stiffness distribution. Smart Struct. Syst. 2017, 19, 11-20. [CrossRef]

24. Lu, G.T.; Li, Y.R.; Wang, T.; Xiao, H.; Huo, L.S.; Song, G.B. A multi-delay-and-sum imaging algorithm for damage detection using piezoceramic transducers. J. Intell. Mater. Syst. Struct. 2017, 28, 1150-1159. [CrossRef]

25. Guo, Y.L.; Zhou, P.; Wang, M.Z.; Pi, Y.L.; Bradford, M.A. Numerical studies of cyclic behavior and design suggestions on triple-truss-confined buckling-restrained braces. Eng. Struct. 2017, 146, 1-17. [CrossRef]

26. Li, Z.; Zhu, B.; Wu, L.; Han, Q. Experimental research on hysteretic behavior of unstiffened tubular n-joints. J. Build. Struct. 2008, 29, 69-74.

27. Yang, W.; Wang, X. Experimental research on seismic behavior of unstiffened overlapped chs k-joints. J. Build. Struct. 2013, 34, 85-92.

28. Yang, W.; Wang, X. Numerical analysis of hysteretic behavior of unstiffened overlapped chs k-joints in steel pipe structures by finite element method. J. Lanzhou Univ. Technol. 2012, 33, 009.

29. Wang, H.; Jing, H.; Zhao, L.; Han, Y.; Lv, X.; Xu, L. Dislocation structure evolution in 3041 stainless steel and weld joint during cyclic plastic deformation. Mater. Sci. Eng. A 2017, 690, 16-31. [CrossRef]

30. Shen, Z.; $\mathrm{Wu}, \mathrm{A}$. Seismic analysis of steel structures considering damage cumulation. Front. Arch. Civ. Eng. China 2007, 1, 1-11. [CrossRef]

31. Shen, Z.Y. A cumulative damage model for the analysis of steel frames under seismic actions. In Proceedings of the Advances in Steel Structures, Hong Kong, China, 15-17 December 1999; pp. 13-24.

32. Sun, Z.; Wang, X. Postbuckling investigations of piezoelectric microdevices considering damage effects. Sensors 2014, 14, 4876. [CrossRef] [PubMed]

33. Shi, Y.; Wang, M.; Wang, Y. Experimental and constitutive model study of structural steel under cyclic loading. J. Constr. Steel Res. 2011, 67, 1185-1197. [CrossRef]

34. Do, V.N.V.; Lee, C.H.; Chang, K.H. A constitutive model for uniaxial/multiaxial ratcheting behavior of a duplex stainless steel. Mater. Des. 2015, 65, 1161-1171.

35. Wang, M.; Fahnestock, L.A.; Qian, F.; Yang, W. Experimental cyclic behavior and constitutive modeling of low yield point steels. Constr. Build. Mater. 2017, 131, 696-712. [CrossRef]

36. Nip, K.H.; Gardner, L.; Davies, C.M.; Elghazouli, A.Y. Extremely low cycle fatigue tests on structural carbon steel and stainless steel. J. Constr. Steel Res. 2009, 66, 96-110. [CrossRef] 
37. Basan, R.; Franulović, M.; Prebil, I.; Kunc, R. Study on ramberg-osgood and chaboche models for 42crmo4 steel and some approximations. J. Constr. Steel Res. 2017, 136, 65-74. [CrossRef]

38. Dundu, M. Evolution of stress-strain models of stainless steel in structural engineering applications. Constr. Build. Mater. 2018, 165, 413-423. [CrossRef]

39. Hassanein, M.F.; Elchalakani, M.; Karrech, A.; Patel, V.I.; Yang, B. Behaviour of concrete-filled double-skin short columns under compression through finite element modelling: Shs outer and shs inner tubes. Structures 2018, 14, 358-375. [CrossRef]

40. Marohnic, T.; Basan, R.; Franulovic, M. Evaluation of methods for estimation of cyclic stress-strain parameters from monotonic properties of steels. Metals 2017, 7, 15. [CrossRef]

41. Szymczak, C.; Kujawa, M. Torsional buckling and post-buckling of columns made of aluminium alloy. Appl. Math. Model. 2018, 60, 711-720. [CrossRef]

42. Zappalorto, M.; Maragoni, L. Nonlinear mode iii crack stress fields for materials obeying a modified ramberg-osgood law. Fatigue Fract. Eng. Mater. Struct. 2018, 41, 708-714. [CrossRef]

43. Ramberg, W.; Osgood, W.R. Description of Stress-Strain Curves by Three Parameters; Technical Note; NationalAdvisory Committee for Aeronautics: Washington, DC, USA, 1943.

44. Corigliano, P.; Crupi, V.; Fricke, W.; Friedrich, N.; Guglielmino, E. Experimental and numerical analysis of fillet-welded joints under low-cycle fatigue loading by means of full-field techniques. Proc. Inst. Mech. Eng. Part C J. Mech. Eng. Sci. 2015, 229, 1327-1338. [CrossRef]

45. Aucott, L.; Huang, D.; Dong, H.B.; Wen, S.W.; Marsden, J.; Rack, A.; Cocks, A.C.F. A three-stage mechanistic model for solidification cracking during welding of steel. Met. Mater. Trans. A Phys. Met. Mater. Sci. 2018, 49A, 1674-1682. [CrossRef]

46. Borgesen, P.; Wentlent, L.; Khasawneh, S.; Shirazi, S.; Schmitz, D.; Alghoul, T.; Greene, C.; Yin, L. A mechanistic thermal fatigue model for snagcu solder joints. J. Electron. Mater. 2018, 47, 2526-2544. [CrossRef]

47. Mac Ardghail, P.; Harrison, N.; Leen, S.B. A through-process, thermomechanical model for predicting welding-induced microstructure evolution and post-weld high-temperature fatigue response. Int. J. Fatigue 2018, 112, 216-232. [CrossRef]

48. Markiewicz, E.; Langrand, B.; Notta-Cuvier, D. A review of characterisation and parameters identification of materials constitutive and damage models: From normalised direct approach to most advanced inverse problem resolution. Int. J. Impact Eng. 2017, 110, 371-381. [CrossRef]

49. Peng, Y.; Wu, C.; Gan, J.; Dong, J. Determination of the local constitutive properties of the welded steel joints using digital image correlation method. Constr. Build. Mater. 2018, 171, 485-492. [CrossRef]

50. Wang, X.L.; Yang, W.W.; Zou, L. Finite element analysis for unstiffened overlapped chs kk-joints welded in different ways. Adv. Mater. Res. 2011, 163-167, 299-306. [CrossRef]

51. Brünig, M.; Gerke, S. Simulation of damage evolution in ductile metals undergoing dynamic loading conditions. Int. J. Plast. 2011, 27, 1598-1617. [CrossRef]

52. Cheng, C.; Li, X. Cyclic experimental studies on damage evolution behaviors of shale dependent on structural orientations and confining pressures. Energies 2018, 11, 160. [CrossRef]

53. Ku-Herrera, J.; Pacheco-Salazar, O.; Ríos-Soberanis, C.; Domínguez-Rodríguez, G.; Avilés, F. Self-sensing of damage progression in unidirectional multiscale hierarchical composites subjected to cyclic tensile loading. Sensors 2016, 16, 400. [CrossRef] [PubMed]

54. Mielke, A. Complete-damage evolution based on energies and stresses. Discret. Contin. Dyn. Syst. Ser. $S$ (DCDS-S) 2012, 4, 423-439.

55. Murakami, S.; Kamiya, K. Constitutive and damage evolution equations of elastic-brittle materials based on irreversible thermodynamics. Int. J. Mech. Sci. 1997, 39, 473-486. [CrossRef]

56. Chinese Code. Gb/700-2006 Carbon Structural Steel; Standards Press of China: Beijing, China, 2006.

57. Chinese Code. Jgj81-2002 Technical Specification for Welding of Steel Structure of Building; Standards Press of China: Beijing, China, 2003.

58. Park, Y.J.; Ang, H.S. Mechanistic seismic damage model for reinforced concrete. J. Struct. Eng. 1985, 111, 722-739. [CrossRef]

59. Krajcinovic, D. Damage Mechanics; Elsevier: New York, NY, USA, 1996; pp. 117-197.

60. Shi, G.; Gao, Y.; Wang, X.; Zhang, Y. Mechanical properties and constitutive models of low yield point steels. Constr. Build. Mater. 2018, 175, 570-587. [CrossRef] 
61. Shi, G.; Wang, M.; Bai, Y.; Wang, F.; Shi, Y.; Wang, Y. Experimental and modeling study of high-strength structural steel under cyclic loading. Eng. Struct. 2012, 37, 1-13. [CrossRef]

62. Christ, H.J.; Mughrabi, H. Cyclic stress-strain response and microstructure under variable amplitude loading. Fatigue Fract. Eng. Mater. Struct. 1996, 19, 335-348. [CrossRef]

63. Mayer, T.; Mazza, E.; Holdsworth, S.R. Parameter evolution in a continuous masing approach for cyclic plasticity and its physical interpretation. Mech. Mater. 2013, 57, 86-96. [CrossRef]

64. Segalman, D.J.; Starr, M.J. Inversion of masing models via continuous iwan systems. Int. J. Non-Linear Mech. 2007, 43, 74-80. [CrossRef]

65. Siddiquee, M.S.A. A pressure-sensitive kinematic hardening model incorporating masing's law. Acta Geotech. 2015, 10, 623-642. [CrossRef]

(C) 2018 by the authors. Licensee MDPI, Basel, Switzerland. This article is an open access article distributed under the terms and conditions of the Creative Commons Attribution (CC BY) license (http:/ / creativecommons.org/licenses/by/4.0/). 